\title{
Reduced Adult Hippocampal Neurogenesis and Working Memory Deficits in the Dgcr8-Deficient Mouse Model of 22q11.2 Deletion-Associated Schizophrenia Can Be Rescued by IGF 2
}

\author{
Yasuo Ouchi, ${ }^{1,2}$ Yuya Banno, ${ }^{2}$ Yuko Shimizu, ${ }^{2}$ Shouta Ando, ${ }^{2}$ Hitoki Hasegawa, ${ }^{1,3}$ Koichi Adachi, ${ }^{4}$ and Takashi Iwamoto ${ }^{1,2}$ \\ ${ }^{1}$ The Center for Education in Laboratory Animal Research and ${ }^{2}$ Department of Biomedical Sciences, College of Life and Health Sciences, Chubu University, \\ Kasugai, Aichi, 487-8501, Japan, and ${ }^{3}$ Division of Cancer Biology and ${ }^{4}$ Radioisotope Research Center Medical Division, Nagoya University Graduate School \\ of Medicine, Sowa-ku, Nagoya, Aichi, 466-8550, Japan
}

DiGeorge syndrome chromosomal region 8 ( $D g c r 8$ ), a candidate gene for 22q11.2 deletion-associated schizophrenia, encodes an essential component for microRNA (miRNA) biosynthesis that plays a pivotal role in hippocampal learning and memory. Adult neurogenesis is known to be important in hippocampus-dependent memory, but the role and molecular mechanisms of adult neurogenesis in schizophrenia remain unclear. Here, we show that $D g c r 8$ heterozygosity in mice leads to reduced cell proliferation and neurogenesis in adult hippocampus, as well as impaired hippocampus-dependent learning. Several schizophrenia-associated genes were downregulated in the hippocampus of $D g c r 8^{+/-}$mice, and one of them, insulin-like growth factor $2(\operatorname{Ig} 2)$, rescued the proliferation of adult neural stem cells both in vitro and in vivo. Furthermore, IGF2 improved the spatial working memory deficits in $\mathrm{Dgcr}^{+/-}$mice. These data suggest that defective adult neurogenesis contributes to the cognitive impairment observed in 22q11.2 deletion-associated schizophrenia and could be rectified by IGF2.

\section{Introduction}

Neurogenesis in the brain of adult mammals occurs throughout life and has been clearly demonstrated in two regions: the subventricular zone (SVZ) of the lateral ventricles and the subgranular zone (SGZ) of the dentate gyrus in the hippocampus (Gage, 2000; Zhao et al., 2008; Ming and Song, 2011).

Recent studies have shown that newborn neurons in the adult hippocampus integrate into the existing circuitry and receive functional input (Ming and Song, 2011). Moreover, defective adult neurogenesis in the hippocampus has been suggested to be involved in learning impairment and the pathophysiology of some psychiatric and neurological disorders, such as schizophrenia and fragile X syndrome (Reif et al., 2006; Mao et al., 2009; Guo et al., 2011). However, despite the fact that a number of neurological disease risk genes have been shown to regulate adult neurogenesis, little is known about the properties of adult neu-

\footnotetext{
Received June 1, 2012; revised April 13, 2013; accepted April 18, 2013.

Author contributions: Y.O. and T.I. designed research; Y.O., Y.B., Y.S., S.A., H.H., and T.I. performed research; H.H. and K.A. contributed unpublished reagents/analytic tools; Y.O., Y.B., Y.S., S.A., and T.I. analyzed data; Y.O. and T.I. wrote the paper.

This study was supported in part by Center of Excellence Project for Private Universities Grant S0801055 from the Ministry of Education, Culture, Sports, Science, and Technology of Japan. We thank Drs. Thoru Shinoe and Yukihiro Baba for their helpful discussion of this work and Rumiko Matsuyama, Miki Yamakawa, Taeko Nakashima, Yuhei Hakumoto, and Takae Hiraide for technical assistance.

The authors declare no competing financial interests.

Correspondence should be addressed to Takashi Iwamoto, Department of Biomedical Sciences, College of Life and Health Sciences, Chubu University, 1200 Matsumoto-cho, Kasugai, Aichi 487-8501, Japan. E-mail: iwamoto@isc.chubu.ac.jp.

DOI:10.1523/JNEUROSCI.2700-12.2013

Copyright $\odot 2013$ the authors $\quad 0270-6474 / 13 / 339408-12 \$ 15.00 / 0$
}

rogenesis in animal models of psychiatric and neurological disorders, and their molecular pathogenesis remains unclear.

Microdeletions at chromosome 22q11.2 are the most common chromosomal deletion, with an incidence of 1 in 2000 4000 live births (Botto et al., 2003). Monoallelic deletion of this genomic region is associated with several clinical defects, most notably DiGeorge syndrome (DiGeorge, 1965) and velocardiofacial syndrome (Shprintzen et al., 1978). Patients with 22q11.2 microdeletion frequently display cognitive and behavioral impairments; in fact, this deletion is one of the best established risk factors for the development of schizophrenia (Pulver et al., 1994; Murphy et al., 1999). So far, 28 genes within the $1.5 \mathrm{Mb}$ region at $22 \mathrm{q} 11.2$ have been identified to be associated with $22 \mathrm{q} 11.2 \mathrm{mi}$ crodeletion syndrome (Karayiorgou et al., 2010), and one of these genes, DiGeorge syndrome chromosomal region 8 (Dgcr8), has been proven to be an essential component of microRNA (miRNA) biosynthesis (Kim, 2005). Hence, dysregulation of miRNA expression in the brain is suspected to be involved in the development of 22q11.2 microdeletion syndrome. Previous analysis suggested that heterologous deletion of $D g c r 8$ in mice might be sufficient for the development of the schizophrenia-like deficits by regulating spine development and dendritic complexity (Stark et al., 2008). However, the molecular mechanisms underlying the development of schizophrenia as well as involvement of hippocampal neurogenesis in these mice are still unclear.

Here, to clarify the contribution and molecular mechanisms of adult neurogenesis in the development of schizophrenia, we generated $\operatorname{Dgcr} 8$ knock-out mice and examined neurogenesis in the hippocampal dentate gyrus of $D g c r 8^{+/-}$mice. Interestingly, 
A
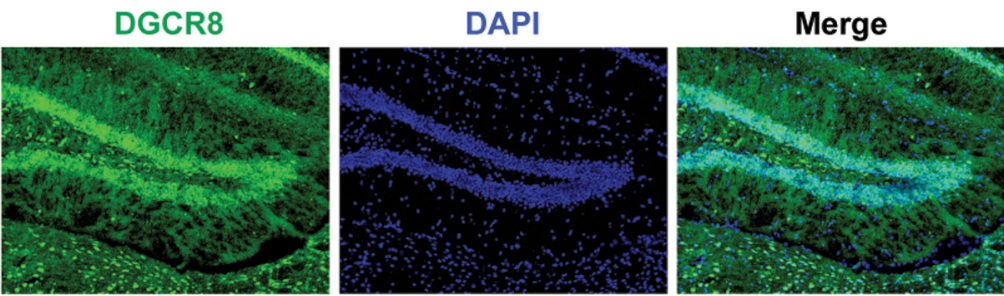

B
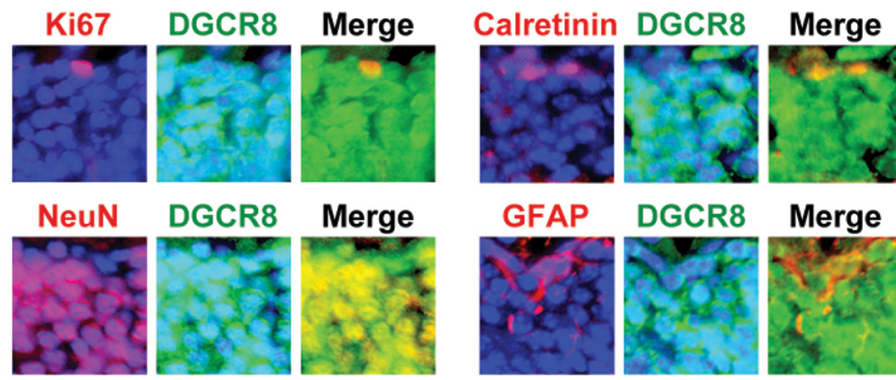

DGCR8
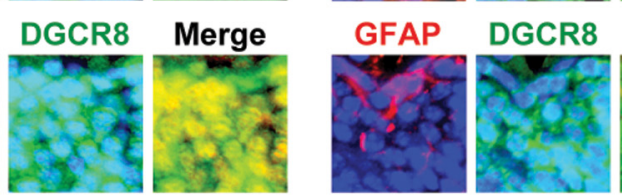

Merge

C

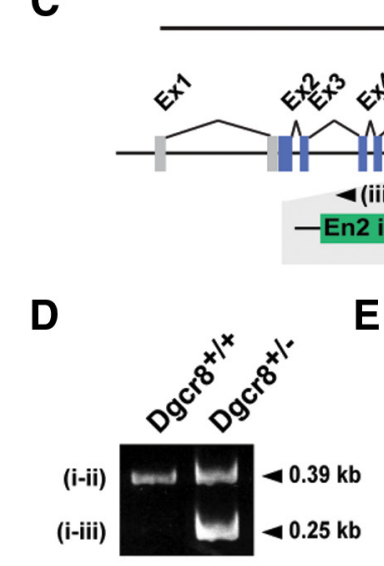

Dgcr8 gene

(i) $>4$ (ii)

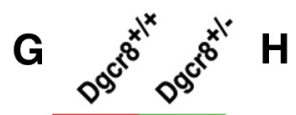

H

\section{E}

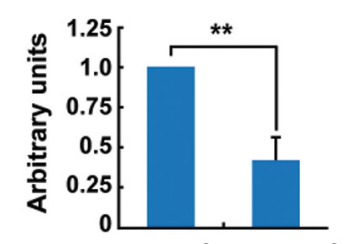

$\mathrm{Dgcr}^{+/+} \mathrm{Dgcr}^{+/-}$

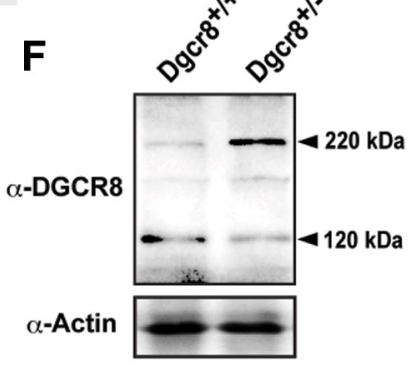

$\mathrm{DGCR}^{+/+} \square \mathrm{Dgcr8}^{+/-}$

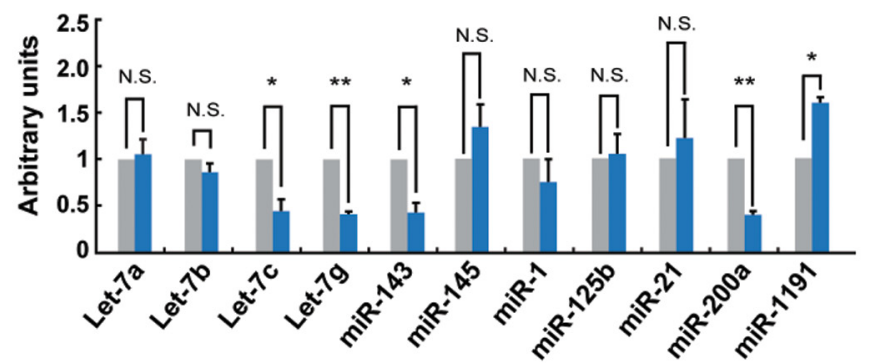

Figure 1. Generation of $\mathrm{Dgcr} 8^{+/-}$mice. $A$, Expression of DGCR8 in the mouse dentate gyrus. Brain sections were stained with anti-DGCR8 antibody (green). The nuclei were stained with DAPI (blue). $\boldsymbol{B}$, Representative images of double immunostaining of anti-DGCR8 (green) with anti-Ki67, anti-Calretinin, anti-NeuN, or anti-GFAP antibodies (red) in the mouse dentate gyrus. The nuclei were stained with DAPI (blue). C, Schematic diagram of the genomic structure of Dgcr8 and intronic gene-trap insertion between exons (Ex) 8 and 9. Black arrowhead indicates approximate genomic location of PCR primers used for genotyping. $\boldsymbol{D}$, Targeted allele was verified by PCR genotyping. Genomic DNA samples extracted from tail snips of $D g c r 8^{+/-}$and $D g c r 8^{+/+}$mice were genotyped using the primers shown in C. E, qRT-PCR analysis confirming reduction in wild-type Dgcr8 mRNA in 2-month-old mouse hippocampus ( ${ }^{* *} p<0.05$, Dgcr8 vs control, two-tailed $t$ test, $n=4$, mean \pm SEM). $F$, Western blotting analysis. Top shows a reduced amount of the $120 \mathrm{kDa}$ wild-type DGCR8 (bottom arrowhead) protein and production of the expected $220 \mathrm{kDa}$ chimeric protein (top arrowhead) in the $D g c r 8^{+/-}$mouse brain, and bottom shows a similar amount of Actin protein. G, miRNA expression profiling in male $D g c r 8^{+/-}$mouse hippocampus. Hierarchically clustered heat map representing differences in miRNA expression in Dgcr8 ${ }^{+/-}$mouse hippocampus. Relative levels of expression are colored from green (low) to red (high). H, qRT-PCR analysis of 11 mature miRNAs in the hippocampus of 2-month-old $\mathrm{Dgcr}^{+/-}$mice ${ }^{*} p<0.05,{ }^{* *} p<0.01, \mathrm{Dgcr}^{+/-}$vs Dgcr $8^{+/+}$, two-tailed $t$ test, $n=4$, mean \pm SEM). the proliferation of adult hippocampal stem/progenitor cells (AHPs) was significantly decreased to downregulate neurogenesis, and the expression of insulin-like growth factor 2 (Igf2), which was found recently to play a critical role in hippocampus-dependent memory consolidation, fear extinction, and AHP proliferation (Agis-Balboa et al., 2011; Chen et al., 2011; Bracko et al., 2012), was dramatically decreased. Moreover, the restoration of IGF2 rescued the proliferation of AHPs both in vitro and in vivo and improve the learning deficits in $\mathrm{Dgcr}^{+/-}$ mice.

\section{Materials and Methods}

Animals. All animal care was in accordance with institutional guidelines and was approved by the Institutional Animal Care and Use Committee of Chubu University.

Generation of Dgcr8 ${ }^{+/-}$mice. A targeted embryonic stem (ES) cell line (XG058) was obtained from BayGenomics in which a gene-trap insertion using a $\beta$-geo cassette caused an interruption in the Dgcr 8 locus. Corresponding ES cell clones were then amplified and injected into C57BL/6 blastocysts. The resulting chimeric males were bred to C57BL/ 6 females to obtain F1 mice.

PCR-based genotyping. Genomic DNA was prepared from tail samples following established procedures. Genotyping was performed using the primers Dgcr8 forward (F), Dgcr8 reverse (R), and Genetrap-R. The expected PCR product from the wild-type Dgcr 8 allele was 387 bp long and that from the trapped $\operatorname{Dgcr} 8$ allele was 248 bp long. The sequences of the primers used were as follows: Dgcr8-F, 5'-TCCTGCTGTGATAAAGTTCCATGAC-3'; Dgcr8-R, 5'-CATGTAATGCCAGAGACATT AGATCCT-3'; and Genetrap-R, 5'-TGCAAG AAGCATGAATCAACTTTGG-3'

RNA extraction. Total RNA was extracted from mouse tissues using Trizol total RNA isolation reagent (Invitrogen) as per the protocol of the manufacturer.

Reverse transcription and real-time $P C R$ quantification of $m R N A$. cDNA was synthesized from $1 \mu \mathrm{g}$ of total RNA using Superscript II reverse transcriptase (Invitrogen) according to the instructions of the manufacturer. Quantitative PCR of mRNA was performed using an ABI Prism 7300 Sequence Detection System (Applied Biosystems), and measurements of SYBR Green (Applied Biosystems) fluorescent dye incorporation were used to calculate the critical threshold cycle number. Critical threshold values were normalized to the values for GAPDH. The sequences of the primers used were as follows: Dgcr8-F2, 5'TGGTGTGACTTACGGATCTG-3'; Dgcr8-R2, 5'-CTTGTCAGCTCATAGACTCG-3'; GAPDH-F, 5'-GTGCCAAGGCTGTGGGCAAG-3'; GAPDH-R, 5'-TTACTCCTTGGAGGCCAT GT-3'; transthyretin (Ttr)-F, 5'-TCGCTG GACTGGTATTTGTG-3'; Ttr-R, 5'-TGCC AAGTGTCTTCCAGTAC-3'; Sulf1-F, 5' -TC 
ACTGGGAAGTACGTGCAT-3'; Sulf1-R, 5' -CAAATCCATGCTTCTCCTTG-3'; AceF, 5' -ACTCAAAGCTGCGAAGGATC-3'; Ace-R, 5' -TGGCATAGCTTCGTGAGGAA3'; Klotho-F, 5'-GCCAGCGATAGTTACAA CAAC-3'; Klotho-R, 5'-GCTCGGCATAAT CCCTGAAA-3'; Otx2-F, 5'-AGCAGAATGG AGGTCAGAAC-3'; Otx2-R, 5'-GAAGCCTGAGTATAGGTCAT-3'; Igf2-F, 5'-GTCGATGTTGGTGCTTCTCA-3'; Igf2-R, 5'-GTC TCCAGGTGTCATATTGG-3'; Htr2c-F, 5'-GC TATGTGTGTTCAGGCATC-3'; and Htr2c-R, 5'-GATTGACCGGCAGCTCTAAA-3' .

Microarray analyses. RNA was isolated using Trizol from 2-month-old $D g c r 8^{+/-}$and $\mathrm{Dgcr}^{+/-}$mouse hippocampus. For gene expression analysis, $100 \mathrm{ng}$ of total RNA was subjected to microarray analysis using a GeneChip Mouse Gene 1.0 ST Array (Affymetrix). Labeling, hybridization, washing, and scanning of the microarray were performed by Bio Matrix Research, following the instructions of the manufacturer. Data analyses were performed using the GeneSpring GX software package (Agilent Technologies).

For miRNA expression analysis, $250 \mathrm{ng}$ of total RNA was subjected to microarray analysis using a miRCURY LNA microRNA Array (Exiqon). Labeling, hybridization, washing, and scanning of the microarray were performed by Cosmo Bio following the instructions of the manufacturer. Data analyses were performed using the R software package ( $\mathrm{R}$ Foundation for Statistical Computing, Vienna, Austria).

Reverse transcription and real-time $P C R$ quantification of miRNA. cDNA was synthesized from total RNA using gene-specific primers according to the TaqMan MicroRNA Assay protocol as per the protocol of the manufacturer (Applied Biosystems). Quantitative PCR of miRNA was performed using an Applied Biosystems 7300 Sequence Detection system. The $10 \mu \mathrm{l}$ PCR reaction contained $0.67 \mu \mathrm{l}$ reverse transcription product, $1 \times$ TaqMan Universal PCR master mix, and $1 \mu$ lof the primer and probe mix, according to the TaqMan MicroRNA Assay protocol (Applied Biosystems). The threshold cycle data were determined using default threshold settings. The threshold cycle was defined as the fractional cycle number at which the fluorescence exceeded the fixed threshold.

Western blotting analyses. Fifty micrograms of total protein extract from the brain of adult mice were loaded onto SDS-PAGE gels for Western blotting. Western blotting was performed by a standard protocol. Antibodies against DGCR8 (Protein Tech Group), IGF2 (Santa Cruz Biotechnology), and $\beta$-Actin (Santa Cruz Biotechnology) were used.

Bromodeoxyuridine injection and detection. To determine cell proliferation and neurogenesis in the hippocampus of trained mice, bromodeoxyuridine (BrdU) solution (Roche) $(10 \mathrm{mg} / \mathrm{ml}$ in PBS) was injected into the peritoneal cavity of 2-month-old mice at a dose of $120 \mathrm{mg} / \mathrm{kg}$. For examination of progenitor proliferation in the dentate gyrus, mice were killed $24 \mathrm{~h}$ after the injection, whereas for examination of progenitor proliferation in the SVZ, mice were killed $2 \mathrm{~h}$ after the injection.

For cell fate analyses, $\mathrm{BrdU}$ solution was injected into mice three times a day for $3 \mathrm{~d}$, and the mice were killed 4 weeks later. BrdU incorporation was visualized as described previously (Wojtowicz and Kee, 2006). Coronal brain sections ( $10 \mu \mathrm{m}$ thick) were cut and pretreated with $2 \mathrm{~N} \mathrm{HCl}$ at $37^{\circ} \mathrm{C}$ for 20 min to denature the DNA. After rinsing in PBS, they were incubated with appropriate antibodies. To quantify the population of BrdU-positive cells in the SGZ and SVZ, the number of BrdU-positive nuclei in each region was counted at least 10 or five sections per animal, respectively.

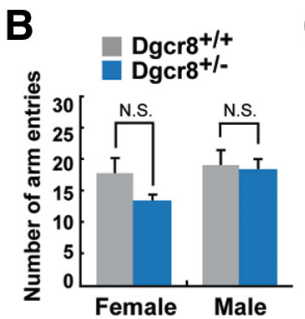

E
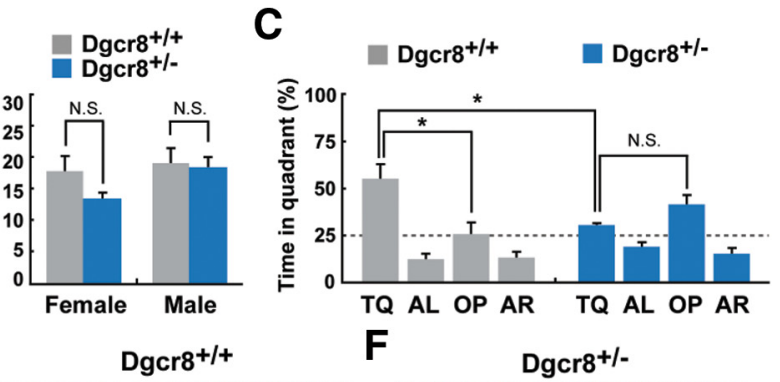

TQ AL OP AR TQ AL OP AR

$\mathbf{F}$
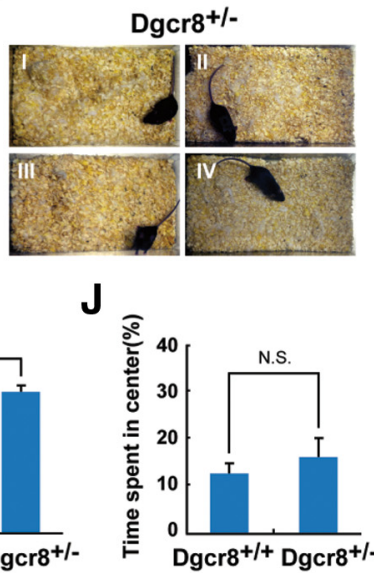
$\mathrm{H}$

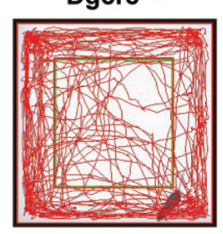

$\mathrm{J}$
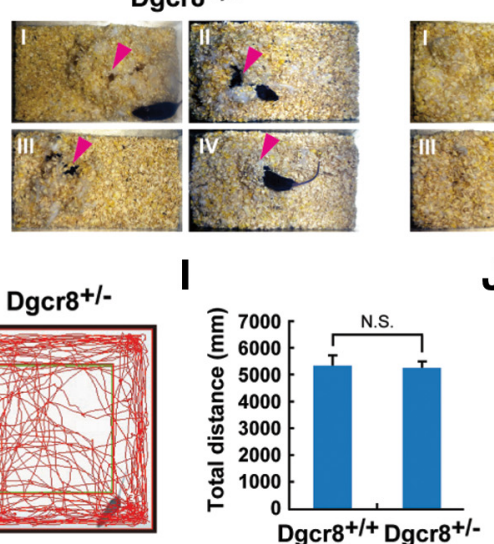

.

Figure 2. Behavior analysis of $D g c r 8^{+/-}$mice. $A, B$, The memory function of 2-month-old $D g c r 8^{+/-}$mice was tested using the spontaneous alternation Y-maze task. Spatial working memory, as assessed by spontaneous alternation performance, was signiftwo-tailed $t$ test $n=10$ mean + SEM).Dgcr8 ${ }^{+/+} n=10$ formales $n=5$ forfemales:Dgcr $8^{+/-} n=10$ formales $n=6$ for females. C, Morris water maze test for spatial learning. $D g c r 8^{+/-}$mice showed a trend toward lower target quadrant occupancy forced-swim test. Immobility times of $D g c r 8^{+/-}$mice were significantly longer than control Dgcr $8^{+/+}$mice $\left({ }^{* * *} p<0.001\right.$ $D g c r 8^{+/-}$vs Dgcr $8^{+/+}$, two-tailed $t$ test, $n=10$, mean \pm SEM). $\boldsymbol{E}, \boldsymbol{F}$, Impaired nesting behavior. Representative pictures of the mice. Pink arrowheads indicated nest. G-J, Exploratory activity of $D g c r 8$ mice and wild-type littermate control mice in an open field. There were no significant differences in the total distance traveled and percent-
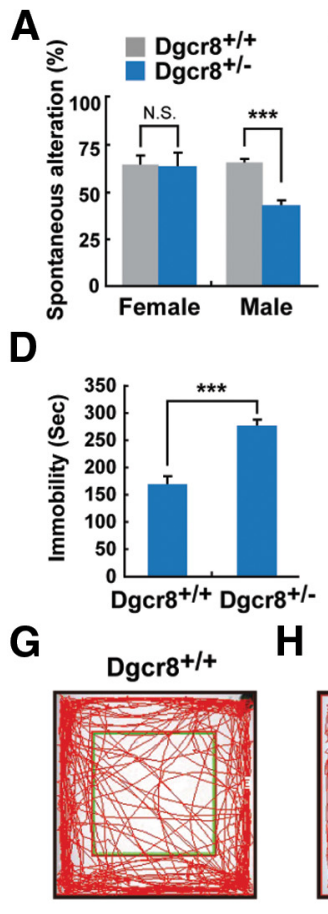

\section{.}

. . 
A

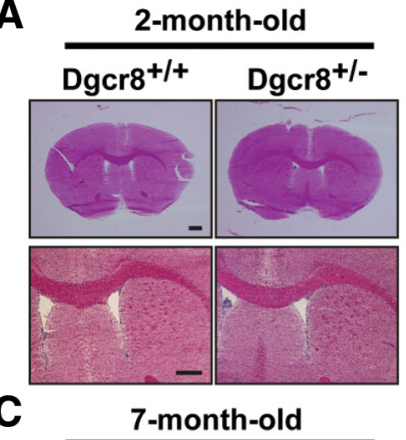

B
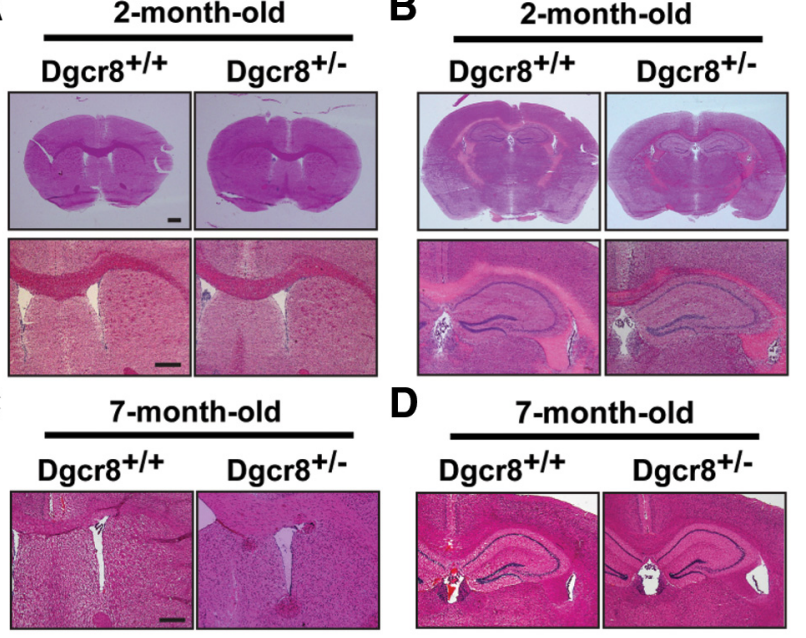

E

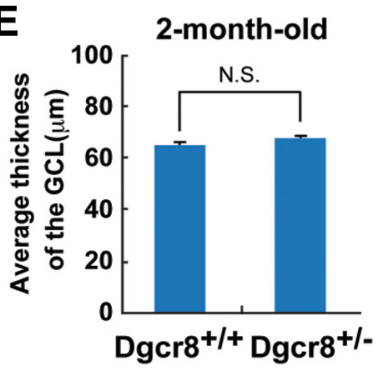

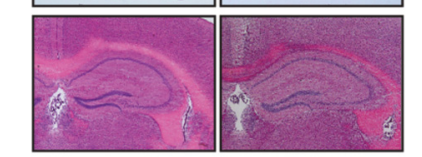

D

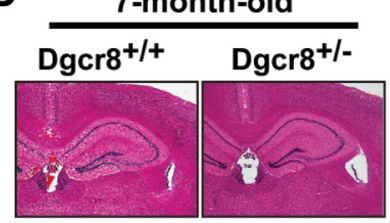

$\mathbf{F}$

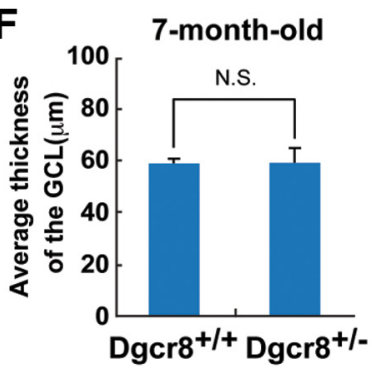

Figure 3. Brain morphology of 2- and 7-month-old $D g c r 8^{+/-}$mice. $\boldsymbol{A}-\boldsymbol{D}$, Hematoxylin and eosin staining of the brains of 2- and 7-month-old $D g c r 8^{+/-}$and $D g c r 8^{+/+}$mice. Coronal brain sections of the lateral ventricle $(\boldsymbol{A}, \boldsymbol{C})$ and hippocampal region $(\boldsymbol{B}, \boldsymbol{D})$ are shown. $\boldsymbol{E}, \boldsymbol{F}$, Average thickness of the dentate gyrus granule cell layer (GCL) in $D g c 8^{+/-}$and $D g c r 8^{+/+}$ mice. Three to four animals in each group and 10 sections from each individual were examined for quantification. Scale bars, $500 \mu \mathrm{m}$.

TUNEL assay. An in situ cell-death detection kit (Roche) was used to detect cell apoptosis in the mouse brain, according to the instructions of the manufacturer.

Neurosphere culture. Adult neurospheres were isolated according to published methods (Bull and Bartlett, 2005). Adult (2 months old) male mice were killed by cervical dislocation, and their brains were immediately removed. For hippocampal cells, a 2 -mm-thick coronal slice was cut between 0.70 and $2.70 \mathrm{~mm}$, relative to bregma, according to an adult mouse brain atlas (Paxinos and Franklin, 2001). The hippocampal area was dissected from the caudal side and carefully trimmed of all white matter. For SVZ cells, the medial and lateral portions of the lateral ventricle subependyma were dissected from both hemispheres. Tissue samples were minced with scissors and enzymatically digested with $0.1 \%$ trypsin-EDTA (Invitrogen) for $10 \mathrm{~min}$ at $37^{\circ} \mathrm{C}$. The digestion was quenched with $0.02 \% \mathrm{w} / \mathrm{v}$ trypsin inhibitor (Wako Chemicals) in PBS.

Cells were plated at a density of 5000 cells $/ \mathrm{ml}$ in uncoated $6 \mathrm{~cm}$ plates (BD Biosciences) containing serum-free DMEM/F-12 medium, supplemented with $20 \mathrm{ng} / \mathrm{ml}$ human recombinant epidermal growth factor (EGF) (Peprotech) and $10 \mathrm{ng} / \mathrm{ml}$ human recombinant basic fibroblast growth factor (bFGF) (Peprotech), N-2 (Invitrogen), B27 (PAA Laboratories), and $100 \mathrm{U} / \mathrm{ml}$ penicillin/streptomycin (Invitrogen). Primary hippocampal cells and SVZ cells were incubated for 2 weeks in humidified $5 \% \mathrm{CO}_{2}$ to permit neurosphere formation. The neurospheres were then counted and collected for immunocytochemistry. For secondary neurosphere formation, cells in primary neurospheres were trypsinized, dissociated mechanically by pipetting and seeded at $2.5 \times 10^{2}$ cells $/ \mathrm{ml}$ per 6 $\mathrm{cm}$ dish. After 2 weeks, the number of secondary neurospheres was counted and their diameters were measured. A minimum cutoff of 20 $\mu \mathrm{m}$ diameter was used to define a neurosphere.

In vivo injection. A microsyringe was inserted into the dorsal hippocampus as described previously (Mira et al., 2010). Briefly, a 32 gauge

microsyringe (Hamilton) was inserted into the left hippocampal dentate gyrus $(-2 \mathrm{~mm}$ anteroposterior, $\pm 1.5 \mathrm{~mm}$ mediolateral from bregma, $-2.3 \mathrm{~mm}$ dorsoventral from the skull) of anesthetized adult mice (2 months old). Then, $2.5 \mu \mathrm{l}$ of either mouse recombinant IGF2 (100 ng/ $\mu \mathrm{l}$ in sterile PBS; R\&D Systems) or PBS was stereotactically injected.

Spontaneous alternation Y-maze test. Spontaneous alternation performance was tested using a symmetrical Y-maze, as described previously (Ohno et al., 2004). Each mouse was placed in the center of the Y-maze and was allowed to explore freely through the maze during a $5 \mathrm{~min}$ session. The movement of each mouse was monitored and analyzed using a SMART animal activity monitoring system (Panlab). The sequence and total number of arms entered were recorded. Arm entry was considered to be complete when the hindpaws of the mouse had been completely placed in the arm. Percentage alternation was defined as the number of triads containing entries into all three arms divided by the maximum possible alternations (the total number of arms entered two) $\times 100$.

Morris water maze test. For 2 consecutive days, mice were trained to find a visible platform that was moved semirandomly among four quadrants of a water tank (a block of four trials). Mice were tested on three blocks separated by $1 \mathrm{~h}$ (a total of 12 trials) per day. Ten days after the first trial, the mice were trained to find a hidden platform for 3 consecutive days. Mice were placed in the middle of the tank and allowed to search the platform for $60 \mathrm{~s}$ and stay on it for $30 \mathrm{~s}$. Mice were trained by three blocks per day for four trials. The next day, the platform was removed, and the mice were placed in the middle of the tank. The test duration was $3 \mathrm{~min}$, during which the time spent in each quadrant was recorded.

Forced-swim test. Each mouse was put in a plastic cylinder, which was half-filled with room temperature water. The test duration was $6 \mathrm{~min}$, during which the immobility times were recorded.

Nesting assay. Two pieces of nesting material, made of cotton fiber, were introduced into a cage in which a mouse was individually housed. Pictures of the nests were taken with a digital camera (DSLR-A100; Sony) after 1 week and exported to a computer.

Open-field test. Activity in a novel open field $(50 \times 50 \times 50 \mathrm{~cm})$ over a 20 min period was measured with a SMART animal activity monitoring system (Panlab).

Statistical analyses. Data were analyzed by the two-tailed Student's $t$ test. Values were expressed as mean \pm SEM. Changes were deemed significant if the $p$ value was $<0.05$. Statistical significance is indicated as follows: ${ }^{\star} p<0.05,{ }^{* \star} p<0.01$, and ${ }^{\star * *} p<0.001$; N.S. indicates not significant.

\section{Results}

\section{Dgcr8 deficiency alters miRNA biogenesis in adult} mouse hippocampus

The Dgcr8 gene encodes an RNA-binding protein that has been proven to play an essential role in miRNA biosynthesis by forming a complex with RNase III enzyme Drosha (Kim, 2005). As a ubiquitous molecule, strong DGCR8 expression was observed in all the cell types in the adult mouse dentate gyrus, including GFAP-positive radial glia-like cells, Ki67-positive proliferating cells, Calretinin-positive immature neurons, and NeuN-positive mature neurons (Fig. $1 A, B$ ). To generate Dgcr8-deficient mice, we used an ES cell line, XG058, in which the insertion of a $\beta$-geo cassette interrupted intron 8 of the $\operatorname{Dgcr} 8$ gene (Fig. 1C). $\mathrm{Dgcr} 8^{+/-}$mice were born at the expected Mendelian ratios, were fertile, and had a normal life expectancy. However, as described previously for $\mathrm{Dgcr} 8^{-/-}$mice derived from another ES cell line, XH157, $\operatorname{Dgcr} 8^{-/-}$mice died at approximately embryonic day 5 because of a generalized cell proliferation defect (Stark et al., 2008).

To determine the expression levels of the wild-type $\operatorname{Dgcr} 8$ gene, we performed qRT-PCR analysis of hippocampus tissue. As expected, the $\operatorname{Dgcr} 8 \mathrm{mRNA}$ level was reduced by approximately half in $\operatorname{Dgcr} 8$ heterozygous mice (Fig. $1 D, E$ ). By Western blotting, we detected a chimeric protein produced as a result of 
the translational fusion between the $\mathrm{N}$-terminal part of DGCR8 and the $\beta$-geo moiety $(\sim 220 \mathrm{kDa})$ and a reduction in the amount of wild-type $120 \mathrm{kDa}$ product (Fig. $1 F)$.

Because one of two functional doublestranded RNA-binding domains of DGCR8 is truncated, the mutant DGCR8 protein is predicted to have no activity in miRNA biosynthesis. To analyze alterations in miRNA biogenesis, we examined miRNA expression by microarray. We isolated RNA from 2-month-old male $\mathrm{DgCr}^{+/-}$and $\mathrm{Dgcr}^{+/+}$mice hippocampus and subjected it to microarray analysis using a miRCURY LNA microRNA Array for differential miRNA expression (Fig. 1G). The microarray data revealed that, although the expression level of a large number of miRNAs was downregulated by $\operatorname{Dgcr} 8$ deficiency as expected, some of the miRNAs were upregulated in the $\operatorname{Dgcr}^{+/-}$hippocampus (Fig. $1 G$ ). We used TaqMAN qRT-PCR to examine the expression of 11 mature miRNAs in hippocampus. Although the expression levels of Let-7c, Let-7g, miR-143, and miR-200a showed a significant decrease in the $D g c r 8^{+/-}$mice hippocampus, that of certain miRNAs, such as Let-7a, Let-7b, miR145, miR-1, miR-125b, and miR-21 remained comparable in $\mathrm{Dgcr}^{+/-}$and $D g c r 8^{+/+}$mice (Fig. 1H). Furthermore, the expression level of miR-1191 was significantly increased, $\sim 1.6$-fold, compared with the control (Fig. $1 H$ ). These results suggested that Dgcr 8 deficiency leads to a more complicated alteration in miRNA biogenesis than expected and may affect the gene expression profile in the hippocampus.

\section{$\mathrm{Dgcr}^{+/-}$mice display cognitive and behavioral deficits}

Next, we analyzed the behavioral and cognitive performance of $\mathrm{Dgcr} 8^{+/-}$mice using various tests. To evaluate the spatial working memory performance of our gene-targeted mice, we first examined spontaneous alternation in the Y-maze tests. Notably, male but not female $D g c r 8^{+/-}$mice showed significantly reduced spontaneous alternation performance in the $\mathrm{Y}$-maze compared with that of wildtype controls (Fig. 2A). Because the total number of arm entries during Y-maze testing was not significantly different between these mice, levels of exploratory activity were not affected by $D g c r 8$ deficiency (Fig. 2B). Thus, we used male $D g c r 8^{+/-}$mice for additional experiments. Performance in the Morris water maze task confirmed that spatial learning and memory performance were affected in $\mathrm{Dgcr}^{+/-}$mice (Fig. 2C). When we used the forced-swim test to assess depression- and anhedonia-like behavior in $\mathrm{Dgcr}^{+/-}$mice, we found increased immobility compared

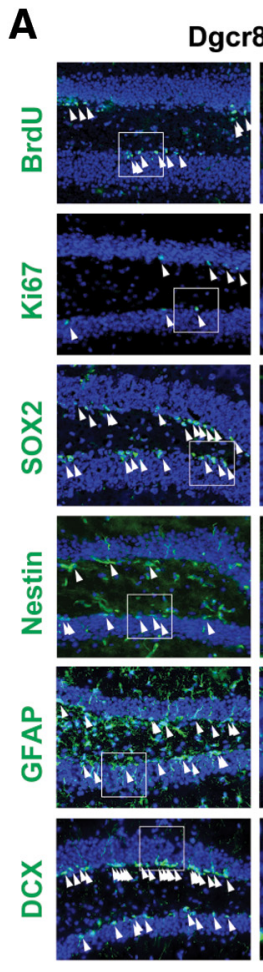

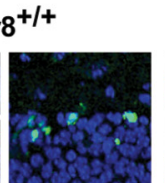
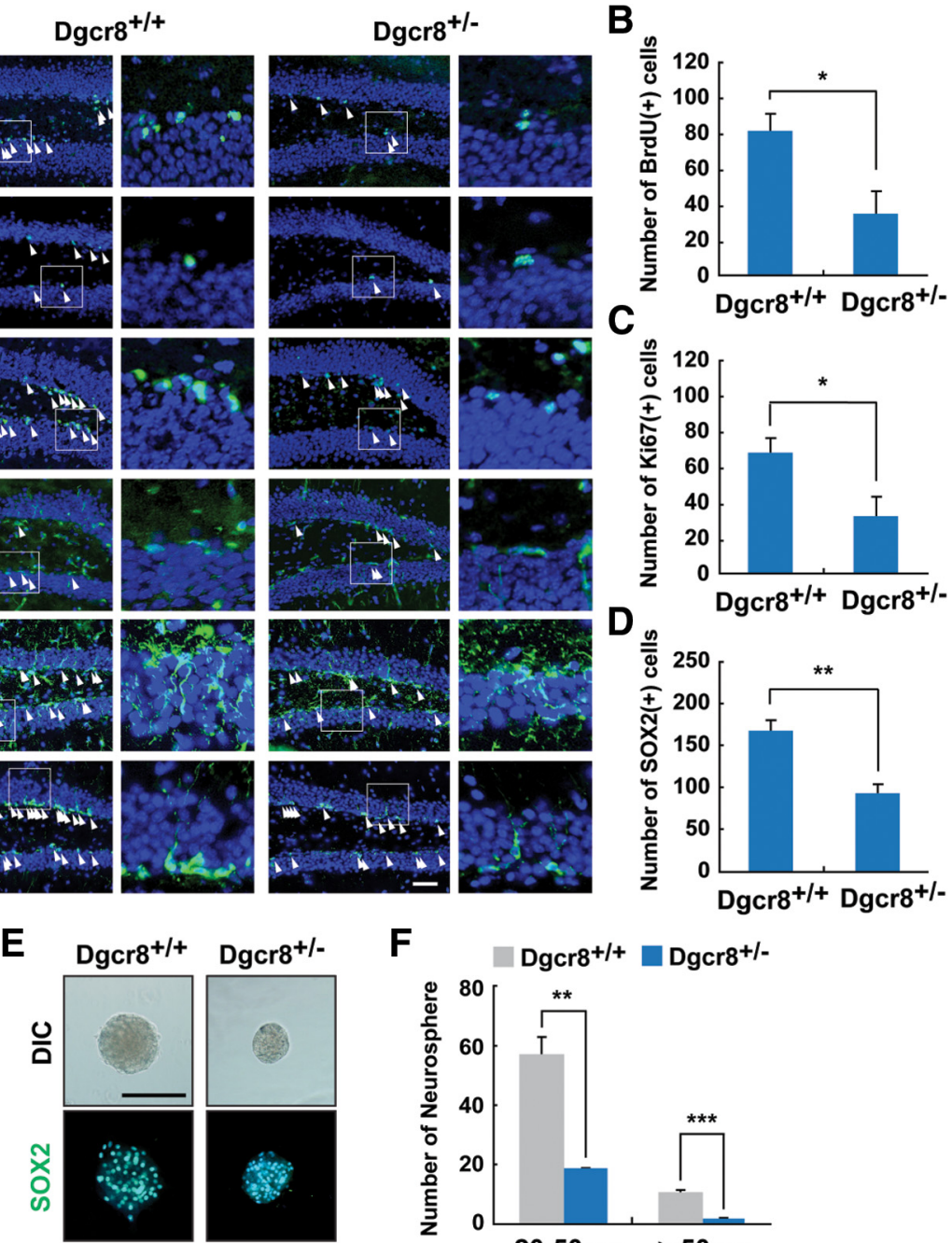

\section{C}
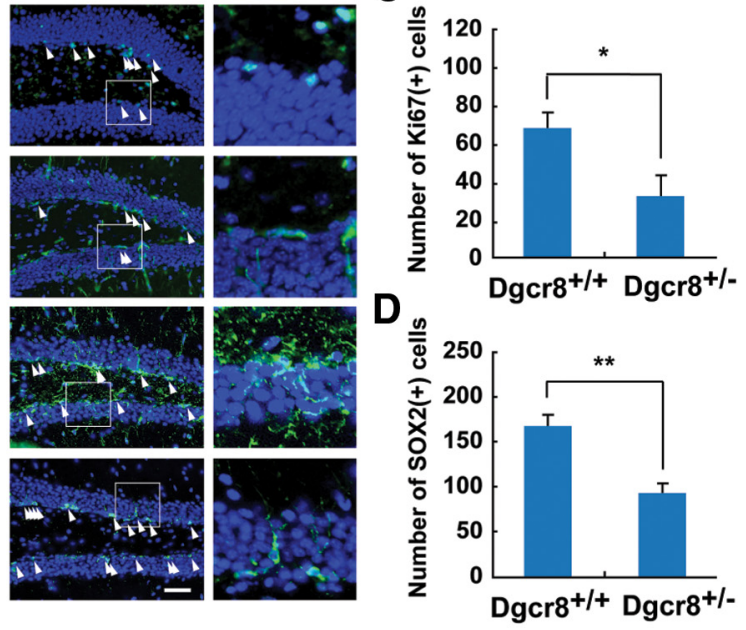

Figure 4. Dgcr8 deficiency affects AHP proliferation in the adult dentate gyrus. $A$, Immunolocalization of neural stem and progenitor cells in the brains of 2-month-old $\mathrm{Dgcr}^{+/+}$and $\mathrm{DgCr}^{+/-}$mice. Brain sections were stained with anti-BrdU, antiKi67, anti-SOX2, anti-Nestin, anti-GFAP, and anti-DCX antibodies (green, white arrowheads). The second and fourth columns from the left show magnified views of the boxed regions. There were decreased numbers of Ki67-, SOX2-, GFAP-, Nestin-, and DCXpositive cells in the brain of $\mathrm{gcrr}^{+/-}$mice compared with those in $\mathrm{Dgcr}^{+/+}$mice. The nuclei were stained with DAPI (blue). Scale bar, $50 \mu \mathrm{m} . \boldsymbol{B}-\boldsymbol{D}$, Quantitative analysis of BrdU-, Ki67-, or SOX2-positive cells in the SGZ. The numbers of BrdU-, Ki67-, and SOX2-positive cells (10 sections per animal) were significantly smaller in the $D g c r 8^{+/-}$mouse hippocampal dentate gyrus ${ }^{*} p<$ $0.05,{ }^{* *} p<0.01, D g c r 8^{+/-}$vs Dgcr $8^{+/+}$, two-tailed $t$ test, $n=3-4$, mean \pm SEM). $E$, Neurosphere cultures derived from the adult hippocampus of $\mathrm{Dgcr} 8^{+/-}$or $\mathrm{Dgcr} 8^{+/+}$mice. Top row, Bright-field images of adult hippocampal neurospheres grown in the presence of bFGF and EGF. Note that the sphere size was decreased in $\mathrm{Dgcr8}{ }^{+/-}$-derived neurospheres. Bottom row, Immunofluorescent microscopy image showing the expression of SOX2 (green) in the neurosphere. The nuclei were stained with DAPI (blue). Scale bars, $100 \mu \mathrm{m}$. $\boldsymbol{F}$, The numbers and sizes of neurospheres generated from $D g c r 8^{+/-}$mice hippocampi were significantly smaller than those generated from $D g c r 8^{+/+}$mice hippocampi ${ }^{* *} p<0.01,{ }^{* * *} p<0.001, D g c r 8^{+/-}$vs Dgcr8 ${ }^{+/+}$, two-tailed $t$ test, $n=3$, mean \pm SEM). DIC, Differential interference contrast.

with wild-type controls (Fig. 2D). Furthermore, we examined the social behavior and locomotor activity of male $\mathrm{Dgcr}^{+/-}$mice using nesting behavior and open-field tests. Although wild-type control mice usually formed an identifiable nest in a distinct location in the cage (Fig. $2 E$ ), $D g c r 8^{+/-}$mice did not generally form distinguishable nests and tended to scatter pieces of nesting material over the floor (Fig. $2 F$ ). Open-field tests showed that there were no significant differences in locomotor activity (Fig. 2G-J).

Together, these data suggest that male $\mathrm{Dgcr} 8^{+/-}$mice exhibit hippocampus-dependent spatial learning, memory, and social behavior deficits and anhedonic behavior. 
A

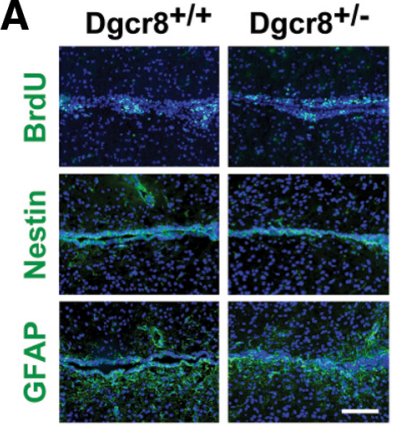

C

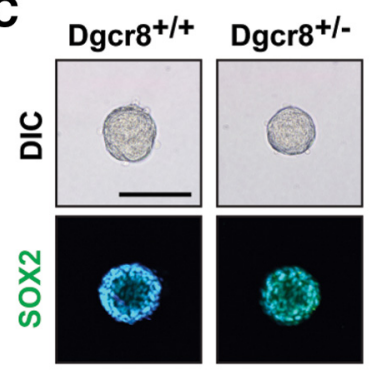

B

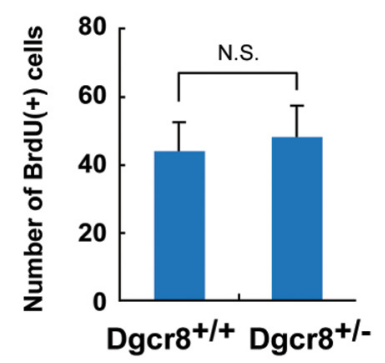

D

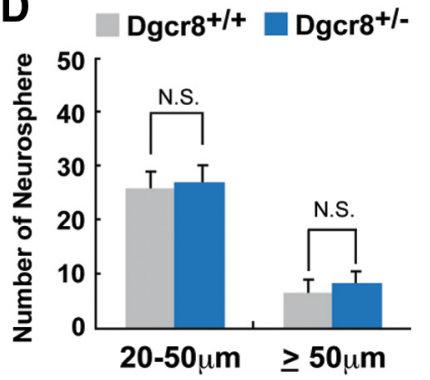

A

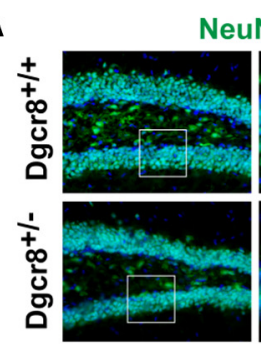

B
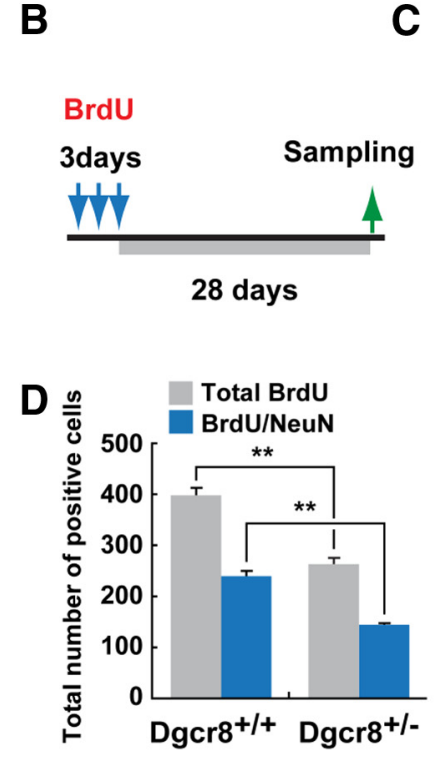

C
Calbindin
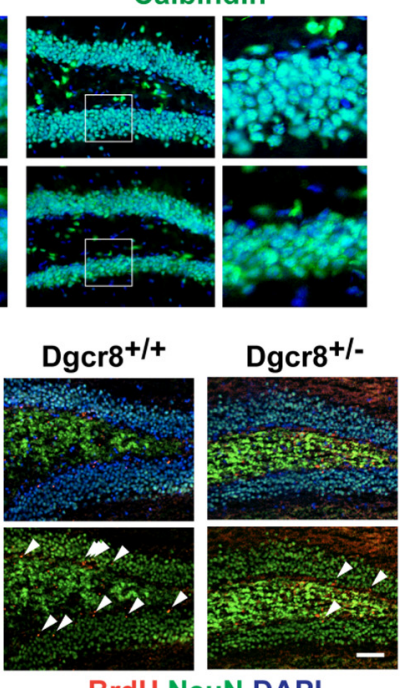

E

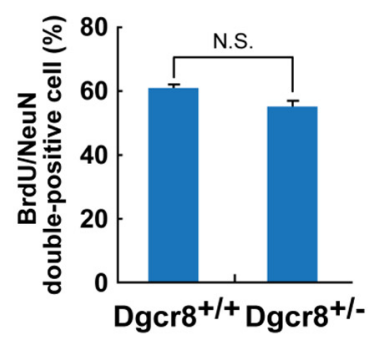

Figure 5. Dgcr8 deficiency does not affect NSC proliferation in the adult SVZ. A, Immunolocalization of neural stem and progenitor cells in the ventrolateral SVZ of 2-month-old $\mathrm{DgCr}^{+/+}$and $\mathrm{Dgcr8}{ }^{+/-}$mice. Brain sections were stained with anti-BrdU, anti-Nestin, and anti-GFAP antibodies (green). The nuclei were stained with DAPI (blue). Scale bar, $100 \mu \mathrm{m} . \boldsymbol{B}$, Quantitative analysis of the number of BrdU-positive cells in the ventrolateral SVZ. For quantitation, BrdU-positive cells were counted over five unbiased images of ventrolateral SVZ at 20X magnification per animal in five animals for each genotype. C, Neurosphere cultures derived from the adult SVZ of $\mathrm{Dgcr} 8^{+/-}$or $\mathrm{Dgcr8}{ }^{+/+}$mice. Top row, Bright-field images of adult SVZ neurospheres grown in the presence of bFGF and EGF. Note that the sphere size was not affected by Dgcr8 deficiency. Bottom row, Immunofluorescent microscopy image showing the expression of SOX2 (green) in the neurosphere. The nuclei were stained with DAPI (blue). Scale bar, $100 \mu \mathrm{m} . \boldsymbol{D}$, Quantitative analysis of the number and size of neurospheres derived from the adult SVZ of $D g c r 8^{+/-}$or $D g c r 8^{+/+}$mice ( $n=3$ each). Note that the number and size of neurosphere were not affected by $D g c r 8$ deficiency.

Dgcr8 deficiency does not affect morphological development of the brain

To analyze the possibility that the behavioral abnormality in $\mathrm{Dgcr}^{+/-}$mice was attributable to abnormal formation of brain structure during development, we first examined the morphology of the brain of 2-month-old $\mathrm{Dgcr} 8^{+/-}$mice by histological analysis. We did not find any remarkable anatomical brain abnormalities in $\mathrm{Dgcr} 8^{+/-}$mice (Fig. $3 \mathrm{~A}, \mathrm{~B}$ ). In addition, the thickness of the granule cell layer and the density of granule cells were not affected in $D g c r 8^{+/-}$mice (Fig. 3 B,E). Furthermore, because the thickness of the granule cell layer is affected during the progression of some hippocampal degeneration (Maekawa et al., 2005), we also examined the thickness of the granule cell layer of 7-month-old $\mathrm{Dgcr}^{+/-}$mice. Similarly, we did not observe any significant difference in $\mathrm{Dgcr}^{+/-}$mice compared with controls (Fig. 3C, $D, F$ ).

These data suggest that $D g c r 8$ deficiency does not obviously affect morphological development and maintenance of the brain.

\section{Proliferation of adult neural progenitor cells is significantly} decreased in the $\mathrm{Dgcr}^{+/-}$mouse hippocampal dentate gyrus but not the SVZ

Recently, adult neurogenesis in the dentate gyrus has been suggested to play an important role in behavioral deficits (Gage, 2000; Zhao et al., 2008; Deng et al., 2010; Ming and Song, 2011; Sahay et al., 2011). We first asked whether deficiency of Dgcr8

Figure 6. Adult neurogenesis in the hippocampal dentate gyrus is decreased in $D g c r 8^{+/-}$ mice. $A$, Immunolocalization of mature neurons in the brain of 2-month-old $\mathrm{gcrr}^{+/+}$and Dgcr8 ${ }^{+/-}$mice. Brain sections were stained with anti-NeuN and anti-Calbindin antibodies (green). The nuclei were stained with DAPI (blue). The second and fourth columns from the left show magnified views of the boxed regions. $\boldsymbol{B}$, Experimental scheme for assessing neurogenesis in the dentate gyrus of $\mathrm{DgCr} 8^{+/+}$and $\mathrm{DgCr} 8^{+/-}$mice. C, Immunolocalization of BrdU (red) and NeuN (green) immunostained cells in the dentate gyrus of $\mathrm{Dgcr}^{+/+}$and $\mathrm{Dgcr}^{+/-}$mice. White arrowhead indicated BrdU/NeuN double-positive cells. The nuclei were stained with DAPI (blue). D, Quantitative analysis of the number of total BrdU and BrdU/NeuN double-positive cells in the dentate gyrus. For quantitation, immunopositive cells were counted over 10 unbiased images at $20 \times$ magnification per animal in three animals for each genotype. The number of both total BrdU and BrdU/NeuN double-positive cells were significantly smaller in the Dgcr8 ${ }^{+/-}$mouse hippocampal dentate gyrus $\left(^{* *} p<0.01, \mathrm{Dgcr}^{+/-}\right.$vs $\mathrm{Dgcr8} 8^{+/+}$, twotailed $t$ test, $n=3$, mean \pm SEM). $E$, Quantitative analysis showing that the percentage of BrdU/NeuN double-positive cells was not affected in $\mathrm{gcr}^{+/-}$mice hippocampus. Scale bar, $50 \mu \mathrm{m}$.

affected the proliferation of AHPs in the dentate gyrus. To label proliferating cells, we administered BrdU intraperitoneally into 2-month-old $D g c r 8^{+/-}$or control littermate mice and killed the mice after $24 \mathrm{~h}$. Interestingly, the number of BrdU-positive cells was significantly downregulated in $\mathrm{Dgcr} 8^{+/-}$mice SGZ (Fig. $4 A, B)$. In addition, Ki67 staining confirmed a significant reduction of proliferating cells in $\mathrm{Dgcr}^{+/-}$mice SGZ (Fig. 4A,C). Immunohistochemical analysis showed that the number of positive cells for neural progenitor markers, such as SOX2, GFAP, and Nestin, in the SGZ was also decreased in $\mathrm{Dgcr} 8^{+/-}$mice (Fig. $4 A, D)$. Moreover, the number of cells positive for the neural progenitor cell/immature neuron marker DCX was also decreased in $\mathrm{Dgcr} 8^{+/-}$mice (Fig. $4 A$ ).

To confirm the decreased proliferation of AHPs seen in the adult $\mathrm{Dgcr} 8^{+/-}$mouse SGZ, we performed neurosphere assays to directly address the proliferative potential of the AHPs. We cultured AHPs isolated from the entire hippocampus at a low den- 
A

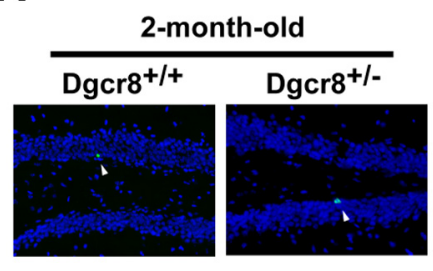

Active Caspase-3 DAPI

C

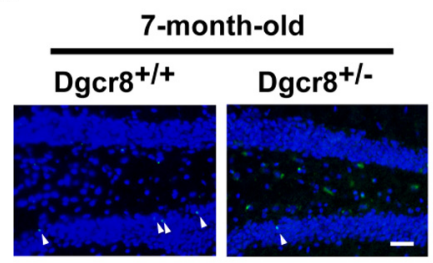

Active Caspase-3 DAPI
B

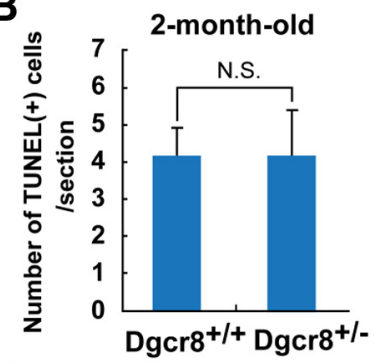

D

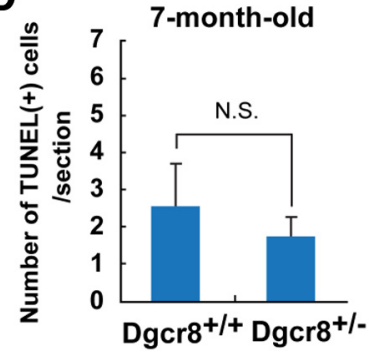

Figure 7. Excess apoptosis was not observed in $\mathrm{Dgcr} 8^{+/-}$mice hippocampus. Apoptotic cells were analyzed in situ by activated caspase 3 immunostaining ( $\boldsymbol{A}, \boldsymbol{C}$ : green, white arrowheads) or DNA fragmentation ( $\boldsymbol{B}, \boldsymbol{D}$ : TUNEL) of adult (2- or 7-month-old) $D g c r 8^{+/+}$and $D g c r 8^{+/-}$mice brain $(n=6-8)$. The nuclei were stained with DAPI (blue). Scale bar, $50 \mu \mathrm{m}$.

sity in the presence of growth factors and examined the number and size of neurospheres to assess whether the ablation of $\mathrm{Dgcr} 8$ would influence neurosphere formation. As we expected, $D g c r 8^{+/-}$-derived neurospheres were smaller than those derived from wild-type mice (Fig. 4E). Immunohistochemical analysis confirmed the expression of SOX2 in these neurospheres (Fig. $4 E$ ). The number of neurospheres formed from $\mathrm{Dgcr} 8^{+/-}$mice hippocampus was decreased $\sim 0.3$-fold compared with those from the control cultures (Fig. $4 F$ ). Additionally, the percentage of spheres $>50 \mu \mathrm{m}$ in diameter was significantly lower in $\operatorname{Dgcr} 8^{+/-}$-derived neurospheres $\left({ }^{*} p<0.05, \mathrm{Dgcr}^{+/-}\right.$vs $\operatorname{Dgcr} 8^{+/+}$, two-tailed $t$ test, $n=3$, mean \pm SEM): $15.4 \%$ in $\mathrm{DgCr}^{+/+}$and $8.27 \%$ in $\mathrm{DgCr} 8^{+/-}$.

When we examined the proliferation of adult neural stem cells (aNSCs) in the SVZ using the same methods, the number of BrdU-positive cells in the SGZ was comparable between $\mathrm{Dgcr}^{+/-}$mice and control littermate mice (Fig. $5 \mathrm{~A}, \mathrm{~B}$ ). Immunohistochemical staining for Nestin and GFAP did not detect any significant difference between these two groups (Fig. 5A). To evaluate the self-renewal potential of aNSCs in the SVZ, we dissociated the primary neurospheres obtained from the SVZ to single cells and replated them to measure secondary neurosphere formation (Fig. $5 C, D$ ). However, we did not observe any significant difference in the size or number of spheres (Fig. $5 C, D$ ).

Hence, the expression of $D g c r 8$ in the adult hippocampus is important for the maintenance of proliferating progenitor cells in the SGZ but not in the SVZ.

\section{Adult neurogenesis is decreased in $\operatorname{Dgcr8}^{+/-}$mouse hippocampal dentate gyrus}

To determine the outcome of the decreased AHP proliferation in the adult hippocampal dentate gyrus induced by $\operatorname{Dgcr} 8$ deficiency, we examined the expression of markers of mature neurons-NeuN and Calbindin-by immunohistochemistry. We did not find any remarkable differences in the positivity for these markers in 2-month-old mice (Fig. 6A). Next, to examine adult neurogenesis in the granule cell layer, we injected BrdU to label the AHPs. After 4 weeks, we quantified the BrdU-positive cells and determined their phenotypes using the neuronal marker NeuN (Fig. 6B,C). Consistent with the decreased number of AHPs, both the number of total BrdU-labeled cells and the number of BrdU/NeuN double-positive cells were significantly decreased in $\mathrm{Dgcr} 8^{+/-}$mice compared with control mice (Fig. $6 C, D)$. However, the percentage of neural differentiation was not significantly altered in the $D g c r 8^{+/-}$hippocampus (Fig. $6 E$ ).

\section{Dgcr8 deficiency does not affect cell survival in the hippocampal dentate gyrus}

Whereas a substantial number of new cells is generated daily during adult neurogenesis, $60-80 \%$ of immature neurons undergo apoptosis and therefore only a subset survive and differentiate into mature neurons (Dayer et al., 2003; Sun et al., 2004). The cell survival of newborn neurons is crucial to maintain a constant supply of mature neurons in the dentate gyrus (Sahay et al., 2011).

To investigate the possibility that the reduction in the number of newborn neurons in $\mathrm{Dgcr} 8^{+/-}$mice was attributable to an increase in cell death, we examined apoptosis in the $\mathrm{Dgcr}^{+/-}$ mouse brain at 2 and 7 months using anti-active caspase 3 antibody staining and TUNEL assays (Fig. $7 A-D$ ). Anti-active caspase 3 immunohistochemical analysis of coronal sections of the dentate gyrus did not show a significant difference between $\mathrm{Dgcr}^{+/-}$and control littermate mice (Fig. $7 \mathrm{~A}, \mathrm{C}$ ). We evaluated the number of apoptotic cells by counting TUNEL-positive cells in the dentate gyrus per section and found no significant increase in apoptotic cell death between $\mathrm{Dgcr} 8^{+/+}$and $\mathrm{Dgcr} 8^{+/-}$mice (Fig. $7 B, D$ ). In addition, there was no excess apoptosis in the lateral ventricles (data not shown).

These results suggest that $D g c r 8$ deficiency does not affect cell survival in the hippocampal dentate gyrus.

\section{Decreased expression of several schizophrenia-associated genes in the $\operatorname{Dgcr}^{+/-}$mice hippocampus}

To gain insight into the molecular mechanisms by which $D g c r 8$ regulates AHPs, we analyzed the expression profile of genes regulated by $D g c r 8$ in the hippocampus using a microarray. We isolated RNA from 2-month-old male $\operatorname{Dgcr} 8^{+/-}$and $D g c r 8^{+/+}$mice hippocampus and analyzed it using an Affymetrix GeneChip Mouse Gene 1.0 ST Array for differential gene expression. Although the expression of most genes was comparable with that in the wild-type controls, that of a subset of genes, including Ace, Klotho, Ttr, Sulf1, Htr2c, Igf2, and Otx2, was dramatically decreased in $\mathrm{Dgcr}^{+/-}$mice hippocampus, (Fig. 8 A, B; Tables 1, 2). To validate the microarray data, we examined the expression level of these genes by qRT-PCR (Fig. 8C). Consistent with the microarray data, we observed a significant decrease in the expression of all these genes (Fig. 8C). For Igf2 expression, Western blotting was performed to verify expression of IGF2 protein (Fig. $8 D$ ). Interestingly, we identified several genes in this group that had been shown previously to be downregulated in schizophrenia patients. For example, TTR has been reported recently to be significantly decreased in the CSF of schizophrenia patients (Huang et al., 2006). HTR2C and SULF1 have been demonstrated to be decreased in schizophrenic prefrontal cortex (Castensson et al., 2005; Narayan et al., 2008), and another group reported that the expression of Ace was decreased in their brains (Arregui et al., 1979). These findings all support the notion that $\mathrm{Dgcr} 8^{+/-}$mice display pathological conditions similar to those of schizophrenics. Surprisingly, we also found a dramatic decrease in Igf2 expression; this factor has been demonstrated recently to play a crucial 
A
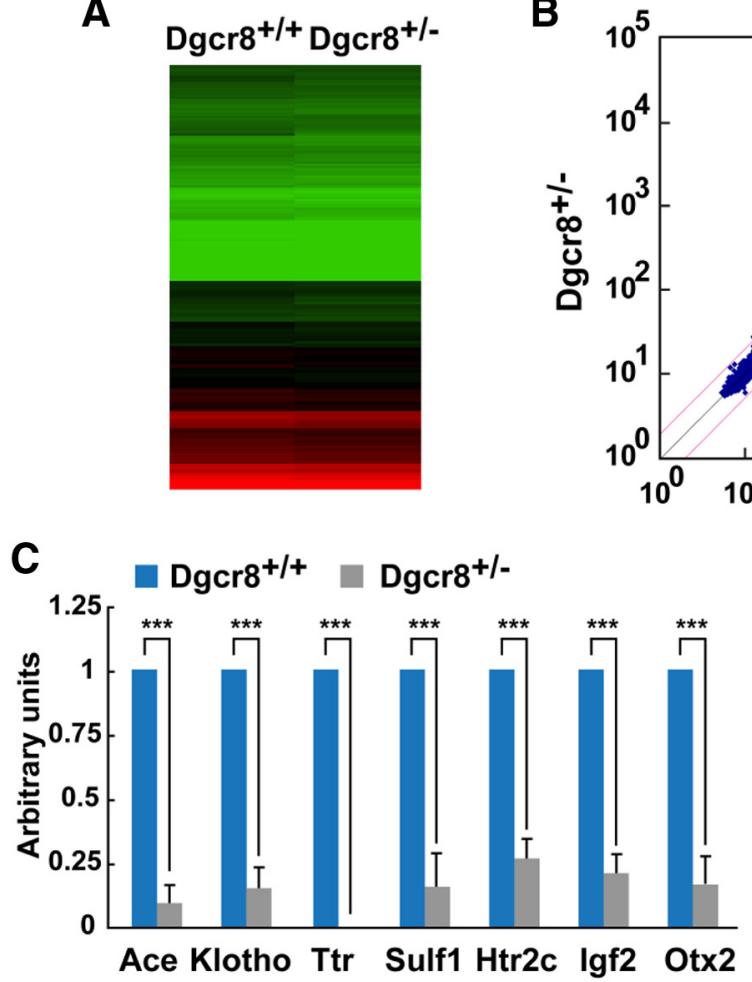

B

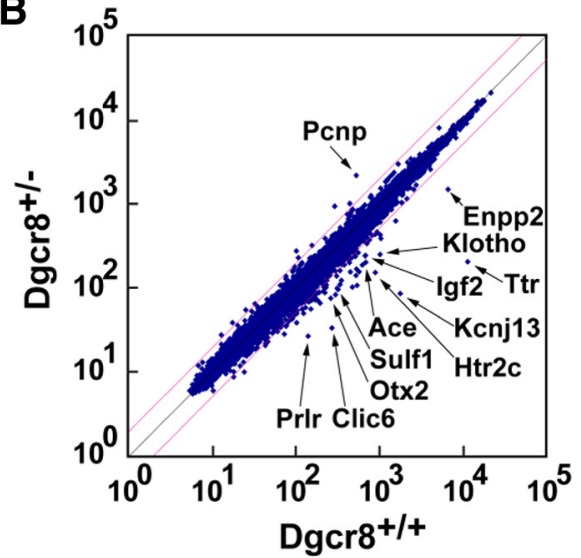

D

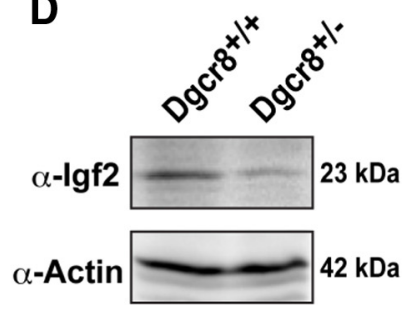

Figure 8. Microarray analysis of $\mathrm{Dgcr} 8^{+/-}$mouse hippocampus identified candidate genes for $22 \mathrm{q} 11.2$ deletion-associated schizophrenia. Gene expression microarray analysis was performed on mRNA isolated from the hippocampus of 2-month-old male $\mathrm{Dgcr}^{+/-}$and $\mathrm{Dgcr} 8^{+/+}$mice. $\mathrm{A}$, Heat map representing hierarchical clustering of $\mathrm{Dgcr}^{+/-}$and $\mathrm{Dgcr} 8^{+/+}$mice hippocampus CDNA microarray data. Red and green squares represent expression levels greater than or less than the mean, respectively. Black squares represent mean expression levels. $\boldsymbol{B}$, Scatter plot depiction of candidate genes involved in 22q11.2 deletion-associated schizophrenia from the microarray comparison of the hippocampus of $\mathrm{Dgcr}^{+/-}$and $\mathrm{Dgcr} 8^{+/+}$mice. C, Quantitative PCR analysis showing significant downregulation of Ace, Klotho, Ttr, Sulf1, Htr2c, Igf2, and Otx2 gene expression in the hippocampus of Dgcr8 $^{+/-}$mice ${ }^{* * *} p<0.001, \mathrm{Dgcr}^{+/-}$vs Dgcr8 ${ }^{+/+}$, two-tailed $t$ test, $n=4$, mean \pm SEM). $D$, Western blotting analysis of IGF2 expression in $D g c r 8^{+/+}$and $D g c r 8^{+/-}$mice hippocampus. Top shows a reduced amount of IGF2 protein in the $D g c r 8^{+/-}$ mouse brain, and bottom shows a similar amount of Actin protein.

role in hippocampal functions, such as memory consolidation and fear extinction (Agis-Balboa et al., 2011; Chen et al., 2011).

IGF2 stimulates proliferation of $\mathrm{Dgcr8}{ }^{+/-}$mice neural progenitor cells both in vitro and in vivo

Because Igf 2 has been quite recently reported to play a pivotal role in both proliferation of NSCs (Lehtinen et al., 2011; Bracko et al., 2012; Ziegler et al., 2012) and hippocampus-dependent memory consolidation (Chen et al., 2011), we first assessed the role of IGF2 signaling in AHPs in the SGZ. To examine the effect of IGF2 on proliferation in vitro, we cultured AHPs in an adherent cell culture system with or without IGF2. As expected, the sizes of the spheres were increased in IGF2-treated $\mathrm{Dgcr} 8^{+/-}$-derived neurospheres (Fig. 9A). Furthermore, the addition of IGF2 enhanced the number of neurospheres formed from $\mathrm{Dgcr} 8^{+/-}$mouse hippocampus approximately twofold compared with control cultures

without IGF2 (Fig. 9B). In IGF2-treated control $\mathrm{Dgcr}^{+/+}$derived neurospheres, although the size of the spheres was comparable, the number of neurospheres was also increased by the addition of IGF2 (Fig. 9B).

To address the role of IGF2 signaling in AHP proliferation in $v i v o$, we injected either $250 \mathrm{ng}$ of recombinant IGF2 or PBS into the dorsal hippocampus of 2-month-old mice and examined the number of SOX2/Ki67 double-positive cells in the SGZ after $3 \mathrm{~d}$.
Consistent with the in vitro results, administration of IGF2 significantly increased the number of AHPs marked by SOX2/Ki67 double-positive cells in the $D g c r 8^{+/-}$mouse SGZ compared with that of PBS-treated $\mathrm{Dgcr}^{+/-}$mice (Fig. $9 C, D)$. We also found a significant upregulation of the number of DCX-positive immature neurons in IGF2-injected $D g c r 8^{+/-}$mice (Fig. 9E,F). Furthermore, to examine adult neurogenesis, we labeled proliferating cells by BrdU and quantified the BrdU/NeuN double-positive cells after 4 weeks (Fig. 9G,H). Consistent with the increased number of AHPs, the number of BrdU/NeuN double-positive cells was also significantly increased in IGF2-injected $D g c r 8^{+/-}$mice compared with that of PBS-injected $\mathrm{Dgcr} 8^{+/-}$mice (Fig. 9G,H). Although the average number of SOX2/Ki67-, DCX-, and BrdU/ NeuN-positive cells were slightly increased in IGF2-injected $\operatorname{Dgcr} 8^{+/+}$ mice compared with PBS-injected controls, these increases were not statistically significant.

These data suggest that IGF2 enhances the proliferation of AHPs and increases the number of neural progenitors and newborn neurons in $\mathrm{Dgcr} 8^{+/-}$mice in vivo.

\section{IGF2 can rescue the behavioral deficits} in $D \mathrm{gcr}^{+/-}$mice

We then assessed whether restoration of Igf 2 expression in the adult hippocampus could rescue the learning deficits in $D g c r 8^{+/-}$mice. To assess the efficacy of IGF2 administration in improving the memory impairment in $\mathrm{Dgcr}^{+/-}$mice, we injected either IGF2 or PBS into the hippocampus of 2-month-old $\mathrm{Dgcr}^{+/+}$and $\mathrm{Dgcr}^{+/-}$mice and tested them for spontaneous alternation in the Y-maze for 4 weeks after administration. Although we did not observe any improvement within 1 week of IGF2 administration (data not shown), spontaneous alternation performance in IGF2-injected $\mathrm{Dgcr}^{+/-}$or $\mathrm{Dgcr} 8^{+/+}$mice gradually increased with time (Fig. $10 A, B)$. After 1 week of injection, IGF2-injected $D g c r 8^{+/-}$mice showed a significant improvement in spontaneous alternation performance in the Y-maze compared with that in PBS-injected $\mathrm{Dgcr}^{+/-}$mice (Fig. 10B). At 2-3 weeks after injection, the performance of IGF2-injected $\mathrm{Dgcr}^{+/-}$mice increased to levels that exceeded the initial response of wild-type control mice, and no significant differences were found between IGF2-injected $D \mathrm{gcr}^{\mathrm{P}^{+/-}}$ and $\mathrm{Dgcr}^{+/+}$mice (Fig. 10 A,B). Conversely, significant differences were found between PBS-injected $D g c r 8^{+/-}$and $\mathrm{Dgcr}^{+/+}$in the total spontaneous alteration performance $\left(^{* * *} p<0.001, D g c r 8^{+/-}\right.$ + PBS vs $D g c r 8^{+/+}+$PBS, two-tailed $t$ test, $\left.n=33-36\right)$. Throughout the experiments, there was no significant difference in the total number of arm entries during Y-maze testing, suggesting that the levels of exploratory activity were not affected (Fig. 10C).

Together, our data suggest that intrahippocampal administration of IGF2 was able to improve the hippocampus-dependent spatial working memory deficit in $\mathrm{Dgcr} 8^{+/-}$mice. 
Table 1. List of differentially expressed probe sets (downregulated, fold change $<0.4$ ) in the $D G C R 8^{+/-}$mouse hippocampus

\begin{tabular}{|c|c|c|c|c|c|}
\hline & $\begin{array}{l}\text { Probe set } \\
\text { identification number }\end{array}$ & $\begin{array}{l}\text { GenBank } \\
\text { accession number }\end{array}$ & Gene symbol & Gene description & Fold change \\
\hline 1 & 10454192 & D89076 & Ttr & Transthyretin & 0.018 \\
\hline 2 & 10356403 & & Kenj13/LOC100045137 & $\begin{array}{l}\text { Potassium inwardly rectifying channel, subfamily J, member 13/ } \\
\text { similar to inward rectifier potassium channel Kir7.1 }\end{array}$ & 0.048 \\
\hline 3 & 10436958 & BC075706 & Clic6 & Chloride intracellular channel 6 & 0.123 \\
\hline 4 & 10602261 & & $H \operatorname{tr} 2 \mathrm{C}$ & 5-Hydroxytryptamine (serotonin) receptor $2 \mathrm{C}$ & 0.169 \\
\hline 5 & 10423049 & BC096586 & Prlr & Prolactin receptor & 0.190 \\
\hline 6 & 10575693 & BC056927 & Al427515 & & 0.196 \\
\hline 7 & 10539393 & & SIc4a5 & Solute carrier family 4, sodium bicarbonate cotransporter, member 5 & 0.213 \\
\hline 8 & 10428619 & BC058759 & Enpp2 & Ectonucleotide pyrophosphatase/phosphodiesterase 2 & 0.223 \\
\hline 9 & 10527870 & AB005141 & Kl & Klotho & 0.245 \\
\hline 10 & 10395389 & AY255635 & Sostdc1 & Sclerostin domain containing 1 & 0.265 \\
\hline 11 & 10381962 & BC110362 & Ace & Angiotensin I converting enzyme (peptidyl-dipeptidase A) 1 & 0.273 \\
\hline 12 & 10438769 & BC002003 & Cldn1 & Claudin 1 & 0.276 \\
\hline 13 & 10419356 & BC017609 & $0 t \times 2$ & Orthodenticle homolog 2 (Drosophila) & 0.287 \\
\hline 14 & 10478048 & BC004795 & $L b p$ & Lipopolysaccharide binding protein & 0.291 \\
\hline 15 & 10405063 & D31951 & Ogn & Osteoglycin & 0.298 \\
\hline 16 & 10528008 & & Steap2 & Six transmembrane epithelial antigen of prostate 2 & 0.298 \\
\hline 17 & 10543921 & ВC089161 & Slc13a4 & Solute carrier family 13 (sodium/sulfate symporters), member 4 & 0.312 \\
\hline 18 & 10344897 & AY101178 & Sulf1 & Sulfatase 1 & 0.314 \\
\hline 19 & 10547191 & BC093486 & C230095G01Rik & RIKEN CDNA C230095G01 gene & 0.322 \\
\hline 20 & 10351224 & U52925 & F5 & Coagulation factor $V$ & 0.334 \\
\hline 21 & 10362104 & BC096454 & Slc2a12 & Solute carrier family 2 (facilitated glucose transporter), member 12 & 0.344 \\
\hline 22 & 10345921 & BC002254 & 1500015010Rik & RIKEN CDNA 1500015010 gene & 0.346 \\
\hline 23 & 10407072 & BC005602 & Elovl7 & ELOVL family member 7, elongation of long chain fatty acids (yeast) & 0.354 \\
\hline 24 & 10365974 & BC132521 & $D c n$ & Decorin & 0.358 \\
\hline 25 & 10530269 & BC112902 & Rbm47 & RNA binding motif protein 47 & 0.368 \\
\hline 26 & 10569344 & BC058615 & $\operatorname{lgf2}$ & Insulin-like growth factor 2 & 0.372 \\
\hline 27 & 10600024 & AF065145 & Gpr50 & G-protein-coupled receptor 50 & 0.380 \\
\hline 28 & 10357328 & & & & 0.389 \\
\hline 29 & 10402195 & BC120793 & $T C 2 n$ & Tandem C2 domains, nuclear & 0.390 \\
\hline 30 & 10495712 & AF000149 & Abca4 & ATP-binding cassette, sub-family A ( $A B C 1)$, member 4 & 0.394 \\
\hline 31 & 10462039 & & Trpm3 & Transient receptor potential cation channel, subfamily M, member 3 & 0.398 \\
\hline
\end{tabular}

RIKEN, The Institute of Physical and Chemical Research.

Table 2. List of differentially expressed probe sets (upregulated, fold change $>2.5$ ) in the DGCR ${ }^{+/-}$mouse hippocampus

\begin{tabular}{|c|c|c|c|c|c|}
\hline & Probe set identification number & GenBank accession number & Gene symbol & Gene description & Fold change \\
\hline 1 & 10544570 & BC132588 & Pcnp & PEST proteolytic signal containing nuclear protein & 4.08 \\
\hline 2 & 10435787 & & & & 3.22 \\
\hline 3 & 10598081 & & & & 2.69 \\
\hline
\end{tabular}

\section{Discussion}

We show here that heterozygosity for $D g c r 8$, a candidate gene for 22q11.2 deletion syndrome, decreases proliferation of AHPs in the dentate gyrus and results in decreased neurogenesis. Administration of exogenous IGF2 restored proliferation of $\mathrm{Dgcr} 8^{+/-}$ AHPs both in vitro and in vivo and improved the learning deficits in $\mathrm{gcrr}^{+/-}$mice. Our data suggest that defective adult neurogenesis may contribute to the learning impairment observed in 22q11.2 deletion-associated schizophrenia and that these learning deficits could be rectified by IGF2.

The functional relevance of adult hippocampal neurogenesis has long been a matter of debate, but accumulating evidence in recent years strongly indicates its essential role in learning and memory formation. Recently, Guo et al., 2011 clearly demonstrated the functional significance of adult neurogenesis using adult nestin-expressing precursor cell-specific conditional deletion of the fragile $\mathrm{X}$ mental retardation protein (Fmrp; responsible for fragile X syndrome) in mice. Moreover, disrupted in schizophrenia 1 (DISC1; a protein implicated in major mental disorders) was shown to promote proliferation of neural progenitors through the GSK3 $\beta / \beta$-catenin pathway, and GSK3 $\beta$ inhib- itor rescued the proliferation and behavior defect caused by DISC1 knockdown in adult mice (Mao et al., 2009).

Consistent with these observations, we found that proliferation of AHPs was dramatically decreased in our mouse model of 22q11.2 deletion-associated schizophrenia. Restoration of progenitor proliferation by IGF2 administration was sufficient to rescue the behavioral defects caused by $D g c r 8$ heterozygosity. These findings suggest that impairment of AHP proliferation in the hippocampus may be sufficient for the development of psychotic disorders and could be rescued by manipulations that induce the proliferation of AHPs. Given the fact that reduced cell proliferation in the hippocampus has also been found in brain specimens of schizophrenics (Reif et al., 2006), AHPs in the hippocampal dentate gyrus might provide a novel therapeutic target for psychotic disorders, especially schizophrenia.

To gain insight into the molecular mechanisms underlying the observed behavioral deficits in $D g c r 8^{+/-}$mice, we examined gene expression profiles in the hippocampus of $\mathrm{Dgcr}^{+/-}$mice. Excitingly, we identified several new candidate genes for 22q11.2 deletion-associated schizophrenia. Other investigators previously used microarray analysis to examine the gene expression 
A

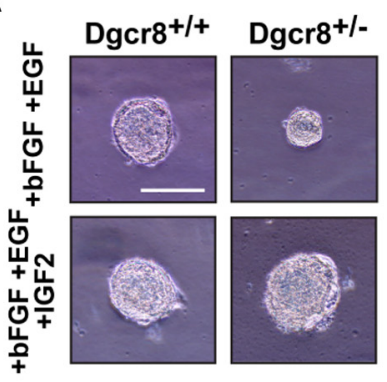

B

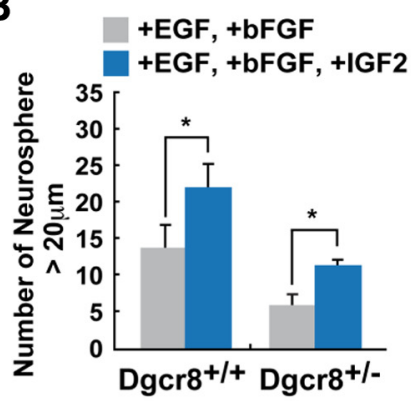

C
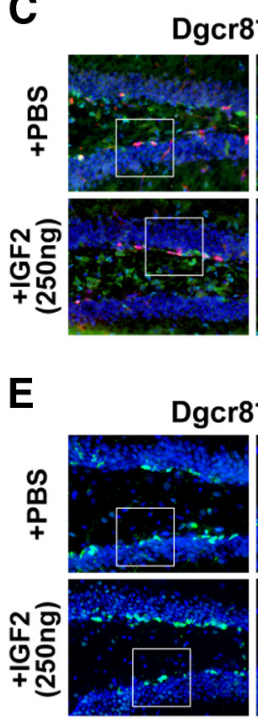

Dgcr8 $+1+$

SOX2 Ki67 DAP
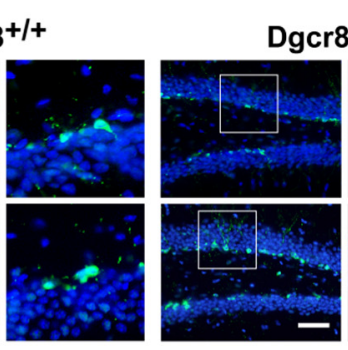

DCX DAPI
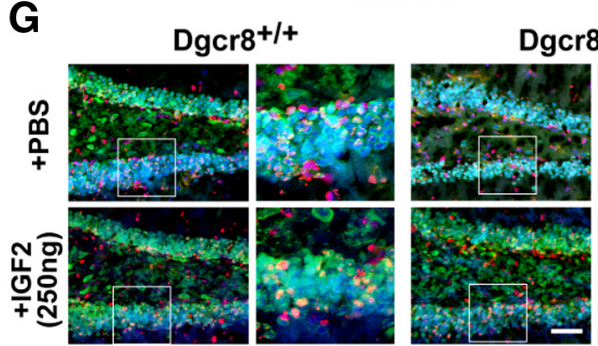

Dgcr8+l-

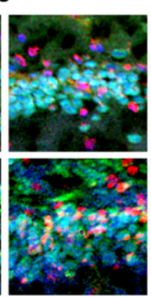

NeuN BrdU DAPI
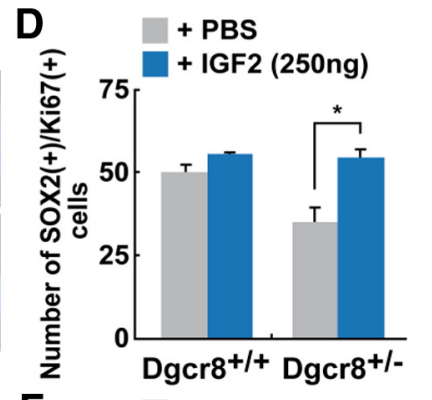

$\mathbf{F}$
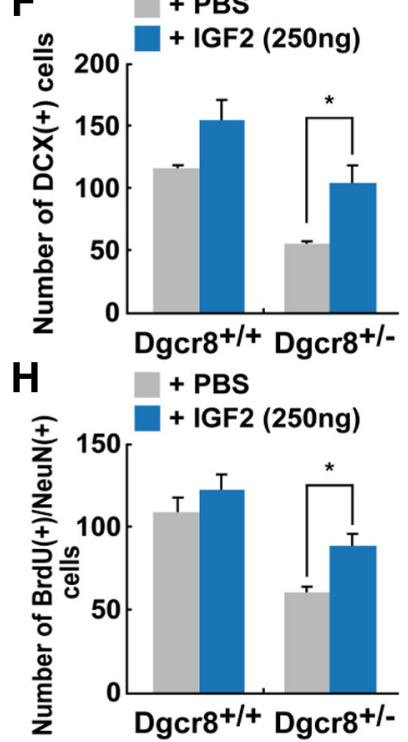

Figure 9. IGF2 stimulated proliferation of $\mathrm{Dgcr}^{+/-}$neural progenitor cells both in vitro and in vivo and rectified the hippocampus-dependent spatial working memory deficits in $D g c r 8^{+/-}$mice. $\boldsymbol{A}$, Bright-field image of neurospheres cultured in the indicated conditions. Neurospheres derived from $D g C r 8^{+/+}$and $D g c r 8^{+/-}$mice hippocampus were cultured in serum-free neurosphere medium in the presence or absence of IGF2. Note that the size of neurosphere was increased by IGF2 stimulation. Scale bar, $100 \mu \mathrm{m}$. $\boldsymbol{B}$, Quantification of the number of sphere-forming progenitors in each condition ( $n=3$ each). Note that the number of neurosphere was increased by IGF2 stimulation $\left(^{*} p<0.05, \mathrm{Dgcr}^{+/+}+\mathrm{EGF}+\mathrm{bFGF}+\mathrm{IGF} 2 \mathrm{vs}\right.$ Dgcr8 ${ }^{+/+}+\mathrm{EGF}+\mathrm{bFGF}$, two-tailed $t$ test, $n=3$, mean \pm SEM; ${ }^{*} p<0.05$, Dgcr $8^{+/-}+$EGF + bFGF + IGF2 vs Dgcr ${ }^{+/-}+$EGF + bFGF, two-tailed $t$ test, $n=3$, mean \pm SEM). $C, E, G$, Immunolocalization of proliferating neural progenitor cells, immature neurons, and terminally differentiated neurons in the dentate gyrus after intrahippocampal administration of PBS or IGF2. Three days after injection, brains were harvested and then brain sections were stained with anti-S0X2 (green), anti-Ki67 (red), and anti-DCX (green) antibodies (C, $\boldsymbol{E})$. For terminally differentiated neurons, brains were harvested at $28 \mathrm{~d}$ after injection and then stained with anti-BrdU (red) and anti-NeuN (green) antibodies (G). The number of SOX2/Ki67-, DCX-, and BrdU/NeuN-positive cells in the Dgcr8 ${ }^{+/-}$brain was increased $(\boldsymbol{C}, \boldsymbol{E}, \boldsymbol{G})$. The nuclei were stained with DAPI (blue). The second and fourth columns from the left show magnified views of the boxed regions. Scale bar, $50 \mu \mathrm{m} . \boldsymbol{D}, \boldsymbol{F}, \boldsymbol{H}$, Quantification of the number of SOX2/Ki67-, DCX-, and NeuN/BrdU-positive cells in the dentate gyrus. For quantitation, immunopositive cells were counted over five unbiased images at $20 \times$ magnification per animal in three animals for each genotype. Note that the number of SOX2/Ki67-, DCX-, and NeuN/BrdU-positive cells in Dgcr8 ${ }^{+/-}$ was increased by IGF2 administration ( ${ }^{*} p<0.05, \mathrm{Dgcr}^{+/-}+\mathrm{IGF2} \mathrm{vsDgcr}^{+/-}+$PBS, two-tailed $t$ test, $n=3$, mean \pm SEM).

pattern of a mouse model carrying a hemizygous $1.3 \mathrm{Mb}$ chromosomal deficiency $\left[\left(D f(16) A^{+/-}\right.\right.$, ranging from $\operatorname{Dgcr} 2$ to Hira $\left.)\right]$ (Stark et al., 2008), but the specific $D g c r 8$-downstream genes have not been elucidated.
By gene-class testing based on Gene Ontology terms, Stark et al., 2008 found that the expression of synapse- and coated vesicle-associated genes was altered in $D f(16) A^{+/-}$mice; however, our microarray results are rather inconsistent with this. Although the expression of most genes was unaltered in $\mathrm{Dgcr} 8^{+/-}$mice hippocampus, the expression of a subset was dramatically decreased. Notably, most of these genes have been reported previously to be associated with schizophrenia (Castensson et al., 2005; Huang et al., 2006; Narayan et al., 2008), implying that $\mathrm{Dgcr}^{+/-}$mice display pathological conditions similar to those of schizophrenia patients.

Although our microarray data point to a number of interesting genes that certainly merit additional investigation, in the present study, we decided to focus on hippocampal IGF2 signaling. IGF signaling has been implicated in a number of cellular processes including the proliferation of NSCs and may act as a niche factor to maintain stem cells that could potentially contribute to proliferation and spatial memory formation of AHP in our model. Most of IGF2-associated growthpromoting effect actions, if not all, are mediated through the type 1 insulin-like growth factor receptor (IGF1R), a transmembrane heterotetramer protein that possesses intracellular tyrosine kinase activity (Baker et al., 1993; Liu et al., 1993; Efstratiadis, 1998). In contrast, IGF2/ mannose-6-phosphate receptor (IGF2R) has an anti-proliferative function by ensuring the clearance and inactivation of IGF2 in general (Lau et al., 1994; Efstratiadis, 1998).

Previously, expression analysis of IGF receptors in the mouse hippocampus revealed that proliferating progenitors in the SGZ of the dentate gyrus exhibited higher levels of $I g f 1 r$ and lower levels of Igf2 $r$ mRNA (Zhang et al., 2007). Because Igf2 is the most abundantly expressed Igf in the hippocampus (Kar et al., 1993), Igf2 has been proposed to be involved in the proliferation of AHPs in the SGZ. Consistent with this, mutant mice with blunted Igfl $r$ gene expression in nestin-expressing neuronal precursors showed severe brain growth retardation, with a dramatic reduction in dentate gyrus size (Liu et al., 2009). Moreover, Igf2-deficient mice also displayed reduced brain size (Baker et al., 1993).

Intriguingly, consistent with our results, recent gene expression profiling of aNSCs and their neuronal progeny revealed IGF2 to be an autocrine regulator of aNSCs in the SGZ but not in the SVZ (Bracko et al., 2012). These authors showed that the 


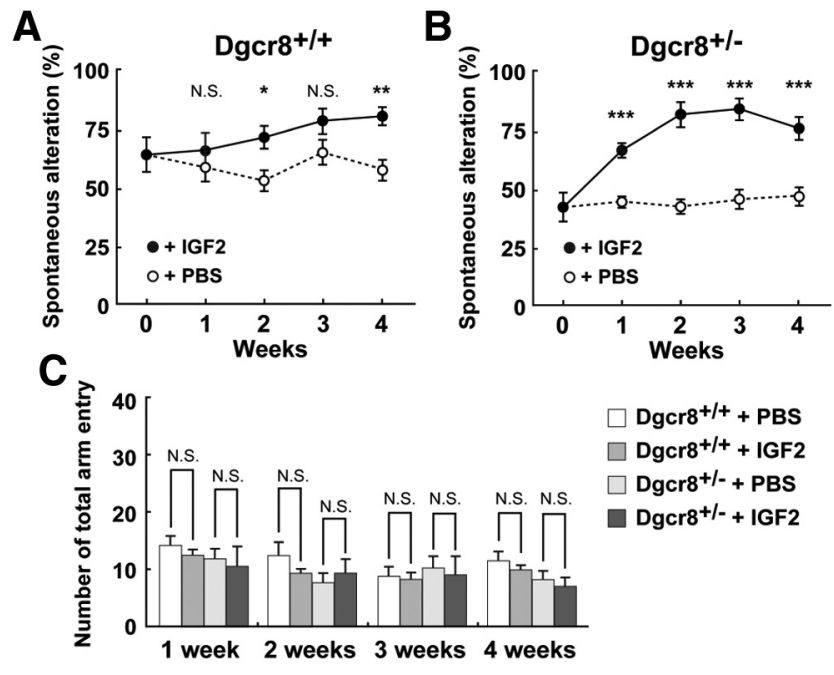

Figure 10. $\quad \boldsymbol{A}, \boldsymbol{B}$, Spatial working memory, as assessed by spontaneous alternation $Y$-maze task at $1,2,3$, and 4 weeks after intrahippocampal administration of PBS or IGF2 $\left(\boldsymbol{A}, \mathrm{Dgcr}^{+/+}\right.$; $\boldsymbol{B}, D g\left(\mathrm{r}^{+/-}\right)$, was significantly rectified by intrahippocampal administration of IGF2 in Dgcr $8^{+/-}$mice $\left(^{*} p<0.05,{ }^{* *} p<0.01\right.$, Dgcr $8^{+/+}+$PBS vs Dgcr ${ }^{+/+}+$IGF2, two-tailed $t$ test, $n=8-9$, mean \pm SEM; ${ }^{* * *} p<0.001, D g c r 8^{+/-}+$PBS vs Dgcr $8^{+/-}+1 \mathrm{IGF} 2$, two-tailed $t$ test, $n=9$, mean \pm SEM). Dgcr $8^{+/+}+$PBS, $n=8-9 ; D g c r 8^{+/+}+1 G F 2, n=$ $9 ; \mathrm{DgCr}^{+/-}+\mathrm{PBS}, n=9 ; \mathrm{Dgcr} 8^{+/-}+\mathrm{IGF} 2, n=9$. Total number of arm entries reflecting exploratory activities of mice in the $Y$-maze does not differ between the groups $(\boldsymbol{C})$.

addition of exogenous IGF2 rescued the proliferation defect in Igf2 knockdown NSCs, whereas the addition of IGF2 to control cells had only a minor effect on NSC proliferation. Consistently, we found that, although IGF2 significantly enhanced proliferation of both $\mathrm{Dgcr}^{+/+}$and $\mathrm{Dgcr} 8^{+/-}$AHPs in vitro with the combination of bFGF and EGF, significant enhancement of AHP proliferation was only observed in the IGF2-injected $\mathrm{Dgcr} 8^{+/-}$ mice. Thus, we speculate that IGF1R is saturated by autocrine IGF2 under physiological conditions and that this autocrine IGF2/IGF1R loop might play a central role in the stem cell niche in the hippocampal dentate gyrus.

Conversely, although the expression levels of several schizophrenia-associated genes were downregulated in the hippocampus of $\mathrm{Dgcr}^{+/-}$mice, the cause of this downregulation remains unknown. One possibility, supported by the results presented here, is miRNA-mediated silencing by upregulated miRNAs. Indeed, we found significant upregulation of miR-1191, whose predicted target is Igf2 (using miRanda-mirSVR) in the hippocampus of $\mathrm{Dgcr}^{+/-}$mice. This potential mechanism requires additional study.

Surprisingly, we found that the deficits in hippocampusdependent learning in $D g c r 8^{+/-}$mice were significantly improved by IGF2 administration. To our knowledge, this is the first evidence to suggest a possible role for IGF2 in the treatment of animal models of schizophrenia.

Recently, two studies have demonstrated a novel and intriguing role for IGF2 in hippocampal function. One study in rats showed that administration of IGF2 significantly enhanced memory retention, promoted the memory proxy, and prevented forgetting through activating synaptic GSK3 $\beta$ and increased GluR1 expression in the short term (Chen et al., 2011). Another mouse-based study showed that fear extinction critically required elevated hippocampal IGF2 signaling, which promotes the survival of 17- to 19-d-old newborn hippocampal neurons (Agis-Balboa et al., 2011). Thus, significance of IGF2 in cognitive and psychiatric disorders is becoming a very important topic. However, our pres- ent findings differ somewhat from the previous ones. In the present study, although increased numbers of AHPs and immature neurons were observed $3 \mathrm{~d}$ after IGF2 administration, we did not observe any cognitive improvement in this short period (data not shown). Interestingly, the spatial working memory performance of IGF2-injected $\mathrm{Dgcr}^{+/-}$mice in the Y-maze gradually increased to levels exceeding the initial response of wild-type control mice at 2 weeks after the injection. Considering that newborn neurons in the adult undergo a critical period of maturation, 1-4 weeks after birth, when they display greater plasticity than fully mature neurons (Zhao et al., 2008), we speculate that integration of newly generated neurons is required for IGF2-dependent spatial working memory formation in $\mathrm{Dgcr} 8^{+/-}$mice.

In $\mathrm{Dgcr} 8^{+/-}$mice, a reduction in the number of AHPs seems not to affect the volume of the dentate gyrus. This result is consistent with recent findings showing that a reduction in the number of aNSCs-derived cells in Fmrp conditional knock-out mice did not affect the overall volume of the dentate gyrus (Guo et al., 2011). Moreover, another studies reported that the number of Ki67-positive cells in the dentate gyrus in C57BL/6J mice were dramatically declined by $90 \%$ from 2 - to 7 -month-old animals, without not affecting the volume of the dentate gyrus (Kitamura and Sugiyama, 2006; Ben Abdallah et al., 2010) Thus, it is possible that a reduction in neurogenesis in $\mathrm{Dgcr}^{+/-}$mice may not obviously affect the thickness of the dentate gyrus.

Our behavioral tests revealed that only male $\mathrm{Dgcr} 8^{+/-}$mice display spatial working memory deficits. Correspondingly, a growing body of evidence suggests that the incidence of schizophrenia is $\sim 40 \%$ higher in men than in women (Kulkarni et al., 2012). Estrogen-protection mechanisms are believed to play a central role in the development of schizophrenia. Although we have not yet examined adult neurogenesis and the effect of estrogen in female $\mathrm{Dgcr} 8^{+/-}$mice, the mRNA expression levels of $D g c r 8$ and Igf2 were downregulated in these mice (data not shown). Additional studies are needed to understand the molecular mechanisms underlying this sexually dimorphic effect.

In summary, our results indicate that downregulation of IGF2 at least in part contributes to the behavioral and neuronal deficits associated with human 22q11.2 deletion-associated schizophrenia by regulating adult neurogenesis. We propose that new therapeutic strategies to enhance IGF2 signaling and adult neurogenesis might be useful for the treatment of this disorder.

\section{References}

Agis-Balboa RC, Arcos-Diaz D, Wittnam J, Govindarajan N, Blom K, Burkhardt S, Haladyniak U, Agbemenyah HY, Zovoilis A, Salinas-Riester G, Opitz L, Sananbenesi F, Fischer A (2011) A hippocampal insulingrowth factor 2 pathway regulates the extinction of fear memories. EMBO J 30:4071-4083. CrossRef Medline

Arregui A, MacKay AV, Iversen LL, Spokes EG (1979) Reduction of angiotensin-converting enzyme in substantia nigra in early-onset schizophrenia. N Engl J Med 300:502-503. CrossRef Medline

Baker J, Liu JP, Robertson EJ, Efstratiadis A (1993) Role of insulin-like growth factors in embryonic and postnatal growth. Cell 75:73-82. CrossRef Medline

Ben Abdallah NM, Slomianka L, Vyssotski AL, Lipp HP (2010) Early agerelated changes in adult hippocampal neurogenesis in C57 mice. Neurobiol Aging 31:151-161. CrossRef Medline

Botto LD, May K, Fernhoff PM, Correa A, Coleman K, Rasmussen SA, Merritt RK, O'Leary LA, Wong LY, Elixson EM, Mahle WT, Campbell RM (2003) A population-based study of the 22q11.2 deletion: phenotype, incidence, and contribution to major birth defects in the population. Pediatrics 112:101-107. CrossRef Medline

Bracko O, Singer T, Aigner S, Knobloch M, Winner B, Ray J, Clemenson GD Jr, Suh H, Couillard-Despres S, Aigner L, Gage FH, Jessberger S (2012) Gene expression profiling of neural stem cells and their neuronal progeny 
reveals IGF2 as a regulator of adult hippocampal neurogenesis. J Neurosci 32:3376-3387. CrossRef Medline

Bull ND, Bartlett PF (2005) The adult mouse hippocampal progenitor is neurogenic but not a stem cell. J Neurosci 25:10815-10821. CrossRef Medline

Castensson A, Aberg K, McCarthy S, Saetre P, Andersson B, Jazin E (2005) Serotonin receptor $2 \mathrm{C}$ (HTR2C) and schizophrenia: examination of possible medication and genetic influences on expression levels. Am J Med Genet B Neuropsychiatr Genet 134B:84-89. CrossRef Medline

Chen DY, Stern SA, Garcia-Osta A, Saunier-Rebori B, Pollonini G, BambahMukku D, Blitzer RD, Alberini CM (2011) A critical role for IGF-II in memory consolidation and enhancement. Nature 469:491-497. CrossRef Medline

Dayer AG, Ford AA, Cleaver KM, Yassaee M, Cameron HA (2003) Shortterm and long-term survival of new neurons in the rat dentate gyrus. J Comp Neurol 460:563-572. CrossRef Medline

Deng W, Aimone JB, Gage FH (2010) New neurons and new memories: how does adult hippocampal neurogenesis affect learning and memory? Nat Rev Neurosci 11:339-350. CrossRef Medline

DiGeorge A (1965) A new concept of the cellular basis of immunity. Disabil Rehabil 67:907-908.

Efstratiadis A (1998) Genetics of mouse growth. Int J Dev Biol 42:955-976. Medline

Gage FH (2000) Mammalian neural stem cells. Science 287:1433-1438. CrossRef Medline

Guo W, Allan AM, Zong R, Zhang L, Johnson EB, Schaller EG, Murthy AC, Goggin SL, Eisch AJ, Oostra BA, Nelson DL, Jin P, Zhao X (2011) Ablation of Fmrp in adult neural stem cells disrupts hippocampus-dependent learning. Nat Med 17:559-565. CrossRef Medline

Huang JT, Leweke FM, Oxley D, Wang L, Harris N, Koethe D, Gerth CW, Nolden BM, Gross S, Schreiber D, Reed B, Bahn S (2006) Disease biomarkers in cerebrospinal fluid of patients with first-onset psychosis. PLoS Med 3:e428. CrossRef Medline

Kar S, Chabot JG, Quirion R (1993) Quantitative autoradiographic localization of $\left[{ }^{125} \mathrm{I}\right]$ insulin-like growth factor I, $\left[{ }^{125} \mathrm{I}\right]$ insulin-like growth factor II, and $\left[{ }^{125} \mathrm{I}\right]$ insulin receptor binding sites in developing and adult rat brain. J Comp Neurol 333:375-397. CrossRef Medline

Karayiorgou M, Simon TJ, Gogos JA (2010) 22q11.2 microdeletions: linking DNA structural variation to brain dysfunction and schizophrenia. Nat Rev Neurosci 11:402-416. CrossRef Medline

Kim VN (2005) MicroRNA biogenesis: coordinated cropping and dicing. Nat Rev Mol Cell Biol 6:376-385. CrossRef Medline

Kitamura T, Sugiyama H (2006) Running wheel exercises accelerate neuronal turnover in mouse dentate gyrus. Neurosci Res 56:45-52. CrossRef Medline

Kulkarni J, Hayes E, Gavrilidis E (2012) Hormones and schizophrenia. Curr Opin Psychiatry 25:89-95. CrossRef Medline

Lau MM, Stewart CE, Liu Z, Bhatt H, Rotwein P, Stewart CL (1994) Loss of the imprinted IGF2/cation-independent mannose 6-phosphate receptor results in fetal overgrowth and perinatal lethality. Genes Dev 8:29532963. CrossRef Medline

Lehtinen MK, Zappaterra MW, Chen X, Yang YJ, Hill AD, Lun M, Maynard T, Gonzalez D, Kim S, Ye P, D’Ercole AJ, Wong ET, LaMantia AS, Walsh CA (2011) The cerebrospinal fluid provides a proliferative niche for neural progenitor cells. Neuron 69:893-905. CrossRef Medline

Liu JP, Baker J, Perkins AS, Robertson EJ, Efstratiadis A (1993) Mice carrying null mutations of the genes encoding insulin-like growth factor I (Igf-1) and type 1 IGF receptor (Igf1r). Cell 75:59-72. CrossRef Medline

Liu W, Ye P, O’Kusky JR, D’Ercole AJ (2009) Type 1 insulin-like growth factor receptor signaling is essential for the development of the hippocampal formation and dentate gyrus. J Neurosci Res 87:2821-2832. CrossRef Medline

Maekawa M, Takashima N, Arai Y, Nomura T, Inokuchi K, Yuasa S, Osumi N
(2005) Pax6 is required for production and maintenance of progenitor cells in postnatal hippocampal neurogenesis. Genes Cells 10:1001-1014. CrossRef Medline

Mao Y, Ge X, Frank CL, Madison JM, Koehler AN, Doud MK, Tassa C, Berry EM, Soda T, Singh KK, Biechele T, Petryshen TL, Moon RT, Haggarty SJ, Tsai LH (2009) Disrupted in schizophrenia 1 regulates neuronal progenitor proliferation via modulation of GSK3beta/beta-catenin signaling. Cell 136:1017-1031. CrossRef Medline

Ming GL, Song H (2011) Adult neurogenesis in the mammalian brain: significant answers and significant questions. Neuron 70:687-702. CrossRef Medline

Mira H, Andreu Z, Suh H, Lie DC, Jessberger S, Consiglio A, San Emeterio J, Hortigüela R, Marqués-Torrejón MA, Nakashima K, Colak D, Götz M, Fariñas I, Gage FH (2010) Signaling through BMPR-IA regulates quiescence and long-term activity of neural stem cells in the adult hippocampus. Cell Stem Cell 7:78-89. CrossRef Medline

Murphy KC, Jones LA, Owen MJ (1999) High rates of schizophrenia in adults with velo-cardio-facial syndrome. Arch Gen Psychiatry 56:940945. CrossRef Medline

Narayan S, Tang B, Head SR, Gilmartin TJ, Sutcliffe JG, Dean B, Thomas EA (2008) Molecular profiles of schizophrenia in the CNS at different stages of illness. Brain Res 1239:235-248. CrossRef Medline

Ohno M, Sametsky EA, Younkin LH, Oakley H, Younkin SG, Citron M, Vassar R, Disterhoft JF (2004) BACE1 deficiency rescues memory deficits and cholinergic dysfunction in a mouse model of Alzheimer's disease. Neuron 41:27-33. CrossRef Medline

Paxinos G, Franklin KB (2001) The mouse brain in stereotaxic coordinates, Ed 2. London: Academic.

Pulver AE, Nestadt G, Goldberg R, Shprintzen RJ, Lamacz M, Wolyniec PS, Morrow B, Karayiorgou M, Antonarakis SE, Housman D, Kucheriapati R (1994) Psychotic illness in patients diagnosed with velo-cardio-facial syndrome and their relatives. J Nerv Ment Dis 182:476-478. CrossRef Medline

Reif A, Fritzen S, Finger M, Strobel A, Lauer M, Schmitt A, Lesch KP (2006) Neural stem cell proliferation is decreased in schizophrenia, but not in depression. Mol Psychiatry 11:514-522. CrossRef Medline

Sahay A, Scobie KN, Hill AS, O'Carroll CM, Kheirbek MA, Burghardt NS, Fenton AA, Dranovsky A, Hen R (2011) Increasing adult hippocampal neurogenesis is sufficient to improve pattern separation. Nature 472:466470. CrossRef Medline

Shprintzen RJ, Goldberg RB, Lewin ML, Sidoti EJ, Berkman MD, Argamaso RV, Young D (1978) A new syndrome involving cleft palate, cardiac anomalies, typical facies, and learning disabilities: velo-cardio-facial syndrome. Cleft Palate J 15:56-62. Medline

Stark KL, Xu B, Bagchi A, Lai WS, Liu H, Hsu R, Wan X, Pavlidis P, Mills AA, Karayiorgou M, Gogos JA (2008) Altered brain microRNA biogenesis contributes to phenotypic deficits in a 22q11-deletion mouse model. Nat Genet 40:751-760. CrossRef Medline

Sun W, Winseck A, Vinsant S, Park OH, Kim H, Oppenheim RW (2004) Programmed cell death of adult-generated hippocampal neurons is mediated by the proapoptotic gene Bax. J Neurosci 24:11205-11213. CrossRef Medline

Wojtowicz JM, Kee N (2006) BrdU assay for neurogenesis in rodents. Nat Protoc 1:1399-1405. CrossRef Medline

Zhang J, Moats-Staats BM, Ye P, D’Ercole AJ (2007) Expression of insulinlike growth factor system genes during the early postnatal neurogenesis in the mouse hippocampus. J Neurosci Res 85:1618-1627. CrossRef Medline

Zhao C, Deng W, Gage FH (2008) Mechanisms and functional implications of adult neurogenesis. Cell 132:645-660. CrossRef Medline

Ziegler AN, Schneider JS, Qin M, Tyler WA, Pintar JE, Fraidenraich D, Wood TL, Levison SW (2012) IGF-II promotes stemness of neural restricted precursors. Stem Cells 30:1265-1276. CrossRef Medline 